OPEN ACCESS

Edited by:

Zhiyong Li,

Shanghai Jiao Tong University, China

Reviewed by:

Nicole De Voogd,

Naturalis Biodiversity Center,

Netherlands

Marco J. L. Coolen,

Curtin University, Australia

Lu Fan,

Southern University of Science and Technology, China

*Correspondence: Ute Hentschel uhentschel@geomar.de Peter J. Schupp

peter.schupp@uni-oldenburg.de

Specialty section: This article was submitted to

Microbial Symbioses,

a section of the journal

Frontiers in Microbiology

Received: 23 October 2019 Accepted: 27 March 2020

Published: 24 April 2020

Citation:

Steinert G, Busch K, Bayer K, Kodami S, Arbizu PM, Kelly M,

Mills S, Erpenbeck D, Dohrmann M,

Wörheide G, Hentschel U and

Schupp PJ (2020) Compositional

and Quantitative Insights Into

Bacterial and Archaeal Communities of South Pacific Deep-Sea Sponges

(Demospongiae and Hexactinellida).

Front. Microbiol. 11:716.

doi: $10.3389 /$ fmicb.2020.00716

\section{Compositional and Quantitative Insights Into Bacterial and Archaeal Communities of South Pacific Deep-Sea Sponges (Demospongiae and Hexactinellida)}

\author{
Georg Steinert ${ }^{1,2}$, Kathrin Busch ${ }^{1}$, Kristina Bayer ${ }^{1}$, Sahar Kodami ${ }^{3}$, \\ Pedro Martinez Arbizu ${ }^{3}$, Michelle Kelly ${ }^{4}$, Sadie Mills ${ }^{5}$, Dirk Erpenbeck ${ }^{6,7}$, \\ Martin Dohrmann ${ }^{6}$, Gert Wörheide ${ }^{6,7,8}$, Ute Hentschel ${ }^{1,9 *}$ and Peter J. Schupp ${ }^{2,10 *}$ \\ ${ }^{1}$ RD3 Marine Symbioses, GEOMAR Helmholtz Centre for Ocean Research Kiel, Kiel, Germany, ${ }^{2}$ Institute for Chemistry and \\ Biology of the Marine Environment (ICBM), University of Oldenburg, Oldenburg, Germany, ${ }^{3}$ German Center for Marine \\ Biodiversity Research, Senckenberg Research Institute, Wilhelmshaven, Germany, ${ }^{4}$ National Institute of Water \\ and Atmospheric Research, Ltd., Auckland, New Zealand, ${ }^{5}$ National Institute of Water and Atmospheric Research, Ltd., \\ Wellington, New Zealand, ${ }^{6}$ Department of Earth and Environmental Sciences, Paleontology \& Geobiology, \\ Ludwig-Maximilians-Universität München, Munich, Germany, ${ }^{7}$ GeoBio-Center, Ludwig-Maximilians-Universität München, \\ Munich, Germany, ${ }^{8}$ Bayerische Staatssammlung für Paläontologie und Geologie, Munich, Germany, ${ }^{9}$ Christian-Albrecht \\ University of Kiel, Kiel, Germany, ${ }^{10}$ Helmholtz Institute for Functional Marine Biodiversity at the University of Oldenburg \\ (HIFMB), Oldenburg, Germany
}

In the present study, we profiled bacterial and archaeal communities from 13 phylogenetically diverse deep-sea sponge species (Demospongiae and Hexactinellida) from the South Pacific by $16 \mathrm{~S}$ rRNA-gene amplicon sequencing. Additionally, the associated bacteria and archaea were quantified by real-time qPCR. Our results show that bacterial communities from the deep-sea sponges are mostly host-species specific similar to what has been observed for shallow-water demosponges. The archaeal deep-sea sponge community structures are different from the bacterial community structures in that they are almost completely dominated by a single family, which are the ammonia-oxidizing genera within the Nitrosopumilaceae. Remarkably, the archaeal communities are mostly specific to individual sponges (rather than sponge-species), and this observation applies to both hexactinellids and demosponges. Finally, archaeal 16 s gene numbers, as detected by quantitative real-time PCR, were up to three orders of magnitude higher than in shallow-water sponges, highlighting the importance of the archaea for deep-sea sponges in general.

Keywords: 16S rRNA amplicons, archaea, bacteria, Demospongiae, Hexactinellida, Porifera, quantitative realtime PCR (qPCR), South Pacific Ocean

\section{INTRODUCTION}

Marine sponges (Porifera) host a broad range of microorganisms including bacteria, archaea, eukaryotes, and viruses and are therefore considered holobionts (Webster and Thomas, 2016; Pita et al., 2018). Sponges are integral parts of the marine ecosystem as they couple pelagic and benthic ecosystems by virtue of their massive filter-feeding capacities (Vogel, 1977; 
de Goeij et al., 2017; Pita et al., 2018). Sponge-associated symbionts perform critical functions for their host, including among others, the provision of nutrients (particularly, for nitrogen and carbon) and chemical defense which affect host health and functioning (Slaby et al., 2019). The microbial consortia of sponges are represented by diverse prokaryotic communities with $\geq 63$ phyla having been found in sponges so far (Thomas et al., 2016; Moitinho-Silva et al., 2017b). These prokaryotic communities show sponge species-specific patterns that differ in richness, diversity, and structure from the prokaryotic seawater communities. The composition of the sponge symbiont consortia is shaped by host taxonomy in that sponge species have species-specific prokaryotic communities (Pita et al., 2013; Easson and Thacker, 2014; Thomas et al., 2016; Steinert et al., 2017; Cárdenas et al., 2019). Machine learning provided evidence that the dichotomy between high microbial (HMA) and low microbial abundance (LMA) sponges is a main driver of the sponge-associated community patterns (MoitinhoSilva et al., 2017c). Several prokaryotic phyla and taxa were identified as indicator taxa for either one of the two abundance states, such as Chloroflexi (e.g., SAR202, Caldilineaceae), Acidobacteria (e.g., Solibacteres, PAUC37f, Sva725), Poribacteria or Actinobacteria (e.g., Acidimicrobiia) for HMA sponges, or alternatively, Proteobacteria (e.g., Gammaproteobacteria), Bacteroidetes (e.g., Flavobacteriia), and Planctomycetes (e.g., Planctomycetia) for LMA sponges. The global sponge microbiome data revealed further community features, such as the dominance of specialists and generalists within the symbiont communities, a stable core microbiota, and community structure and functional modularity, with abiotic factors influencing the overall sponge microbiota and biotic factors the prokaryotic core (Thomas et al., 2016; Lurgi et al., 2019).

Most sponge microbiome studies have focused on demosponges that were collected from shallow coastal sites in temperate, subtropical, and tropical sampling locations (e.g., Schmitt et al., 2012; Moitinho-Silva et al., 2014; Naim et al., 2014; Thomas et al., 2016; Steinert et al., 2017; Helber et al., 2019). Considering that the deep-sea is the largest, still relatively underexplored habitat on earth, comparably few studies have been conducted on sponges from remote deep-sea or cold-water locations (e.g., Jackson et al., 2013; Kennedy et al., 2014; Reveillaud et al., 2014; Borchert et al., 2017). Antarctic shallow cold-water demosponges host dominant bacterial taxa that are known to be sponge-associated (Webster et al., 2004; Rodríguez-Marconi et al., 2015; Cárdenas et al., 2018, 2019), and Antarctic deep-water demosponges display high levels of host-specificity (Steinert et al., 2019). In addition, sponges from classes other than Demospongiae, i.e., Hexactinellida, Calcarea, and Homoscleromorpha, are still only poorly covered by $16 \mathrm{~S}$ rRNA gene sequencing approaches (but see Xin et al., 2011; Tian et al., 2016) and are consequently still underrepresented in global sponge microbiome surveys. Finally, most microbiome studies have used bacterial universal 16S rRNA gene primers, hence the sponge-associated archaeal communities have largely been missed (but see, e.g., Webster et al., 2010; Schmitt et al., 2012; Thomas et al., 2016; Moitinho-Silva et al., 2017a; for exceptions, covering both bacterial and archaeal diversity).
In North Atlantic deep-sea sponges, Archaea were previously proposed to be important members of a potential deep-sea specific sponge microbial community (Jackson et al., 2013; Kennedy et al., 2014). Archaeal predominance has also been observed in one Arctic deep-water demosponge species (Pape et al., 2006). Ammonia oxidizing archaea (AOA) were identified as the main contributors of nitrification within the cold-water sponge hosts (Hoffmann et al., 2009; Radax et al., 2012; Li et al., 2014). One recent study underlined the importance of AOA in deep-sea sponges using metagenomic data obtained from one glass sponge (Tian et al., 2016).

Our present study aims to contribute to resolving spongeprokaryote relationships from understudied habitats by exploring both bacterial and archaeal communities in demosponges and hexactinellids, which were collected from meso-, bathypelagic, and abyssal depths in the South Pacific Ocean offshore New Zealand. We investigate whether current sponge-microbiota paradigms hold up for those remotely collected and partially novel sponge species. We address the following questions: (a) are general principles of the Demospongiae microbiota also present in Hexactinellida prokaryotic communities, (b) do these sponge-bacterial community principles also apply to the archaeal community structures in marine sponges, and (c) can we compare the observed deep-sea sponge microbiota to the tropical/warm water sponge microbiota? In addition to these main questions, which we addressed using two highthroughput $16 \mathrm{~S}$ rRNA gene sequencing data libraries, we also applied quantitative PCR (qPCR) to a subset of the sponge specimens, because quantitative data are frequently missing in sponge microbiome studies.

\section{MATERIALS AND METHODS}

\section{Sample Processing and Sponge Taxonomy}

During the SO254 expedition of the research vessel "Sonne" in the South Pacific Ocean south- to northeast around New Zealand in February 2017, over 200 sponge specimens, of 96 sponge taxa comprising the Porifera classes Demospongiae and Hexactinellida, were collected by using a remotely operated vehicle (ROV "Kiel 6000"1). Of these 200 sponges, only species collected in at least triplicate were considered in the microbiome analysis. This criterion reduced the investigated sponge diversity to 45 specimens and 13 species. Depths of the nine collecting sites of the sponges included in the analysis ranged from 472 to $4160 \mathrm{~m}$ (Figure 1, Table 1 and Supplementary Table S1). Sponges were placed in coolers with ice packs upon removal from the bioboxes of the ROV. Briefly, the sponges were photographed and subsequently dissected (Supplementary Figure S1). Small tissue sub-samples were instantly frozen for molecular analyses, while larger tissue samples were stored in ethanol $(80 \%)$ as vouchers for morphological identification. All samples were stored at $-80^{\circ} \mathrm{C}$ until further processing (see section "Supplementary Material”). In addition, nine triplicate

\footnotetext{
${ }^{1}$ http://jlsrf.org/index.php/lsf/article/view/160
} 


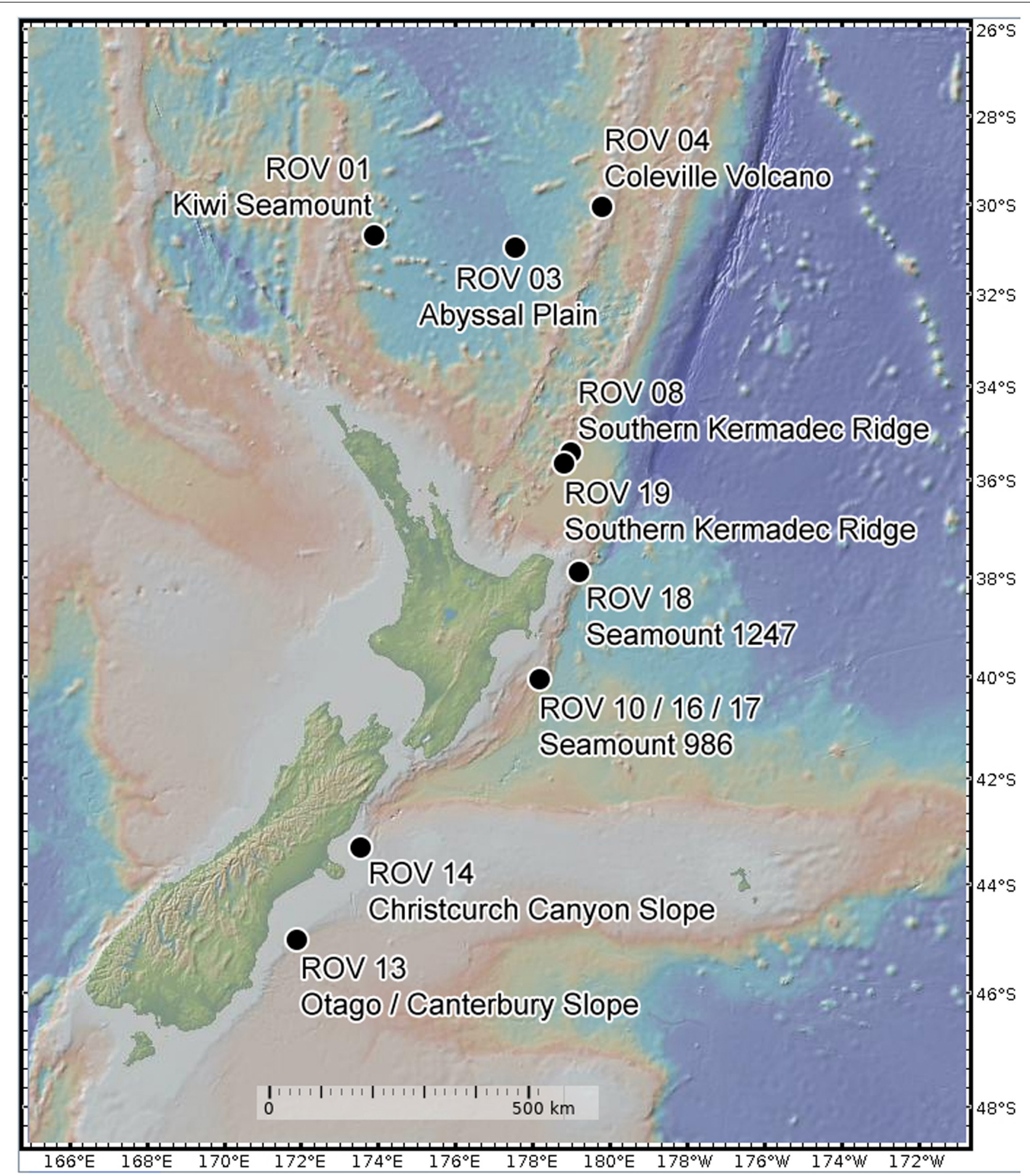

FIGURE 1 | Sampling site map from New Zealand. Dots indicate the collection site with ROV dive number and name of the underwater site.

seawater samples were collected at several sponge sampling sites from the same depths using Niskin bottles attached to the ROV. Approximately $2000 \mathrm{ml}$ of each seawater sample was filtered using PVDF filter membranes $(0.22 \mu \mathrm{m}$ pore size and $\varnothing 47 \mathrm{~mm})$ and stored at $-80^{\circ} \mathrm{C}$ until further processing. Sponge species were identified by morphological and molecular taxonomic methods (see section "Supplementary Material and Table 1"). Sponge tissue vouchers were stored in three collections, NIWA Invertebrate Collection in New Zealand, ICBM Environmental Chemistry Collection, University of Oldenburg, Germany and 
TABLE 1 | Sponge sample list, including taxonomy from class to species, number of replicates, sampling sites, and sampling depths.

\begin{tabular}{|c|c|c|c|c|c|c|}
\hline Class & Order & Family & Genus and species & Replicates & Sampling locations & Sampling depths \\
\hline Demospongiae & Axinellida & Stelligeridae & Paratimea sp. indet. & 4 & Coleville Volcano & $472-532$ \\
\hline Demospongiae & Haplosclerida & Halichondriidae & Halichondria sp. indet. & 3 & Seamount 986 & 892-899 \\
\hline Demospongiae & Poecilosclerida & Latrunculiidae & Latrunculia morrisoni & 3 & $\begin{array}{l}\text { Otago/Canterbury Slope, Christchurch } \\
\text { Canyon Slope }\end{array}$ & $595,670-706$ \\
\hline Demospongiae & Tetractinellida & Geodiidae & Geodia vaubani & 4 & $\begin{array}{l}\text { Southern Kermadec Ridge, Seamount } \\
986\end{array}$ & 1172-1216, 802 \\
\hline Demospongiae & Tetractinellida & Geodiidae & Penares turmericolor & 4 & Southern Kermadec Ridge & $1187-1191$ \\
\hline Demospongiae & Tetractinellida & Pleromidae & Pleroma turbinatum & 3 & Coleville Volcano & $472-497$ \\
\hline Hexactinellida & Lyssacinosida & Euplectellidae & Bolosoma cyanae & 4 & Southern Kermadec Ridge & $1149-1167$ \\
\hline Hexactinellida & Lyssacinosida & Euplectellidae & Corbitella plagiariorum & 4 & Seamount 986 & 770-802 \\
\hline Hexactinellida & Lyssacinosida & Euplectellidae & Regadrella okinoseana & 4 & Seamount 986 & $774-896$ \\
\hline Hexactinellida & Lyssacinosida & Euplectellidae & Saccocalyx tetractinus & 3 & Seamount 1247, Abyssal Plain & $1352-1457,4160$ \\
\hline Hexactinellida & Lyssacinosida & Leucopsacidae & Leucopsacus distantus & 3 & Seamount 986 & $792-896$ \\
\hline Hexactinellida & Lyssacinosida & Rossellidae & Lanuginellinae gen. et sp. indet. & 3 & Seamount 986 & $802-893$ \\
\hline Hexactinellida & Sceptrulophora & Aphrocallistidae & Aphrocallistes beatrix & 3 & Kiwi Seamount, Seamount 986 & $759-793$ \\
\hline
\end{tabular}

For a detailed list see Supplementary Table S1.

Ludwig-Maximilians-Universität, in Germany and are available on request (Supplementary Table S1).

\section{Bacterial and Archaeal 16S rRNA Gene Amplicon Sequencing and Processing}

Initially DNA of sponges (three to four replicates per taxon) and seawater samples was extracted using the DNeasy Power Soil Kit (Qiagen) on approximately $0.25 \mathrm{~g}$ of sponge tissue or half a seawater filter. After the quality and quantity of the extracts had been checked (by Nanodrop and gel electrophoresis after a PCR with universal 16S rRNA gene primers), a one-step PCR was performed for amplification of the bacterial V3 to V4 variable regions (primer pair 341F $5^{\prime}$-CCTACGGGAGGCAGCAG$3^{\prime}$ and 806R 5'-GGACTACHVGGGTWTCTAAT-3') and archaeal V4 to V6 variable regions (primer pair Uni519F $5^{\prime}$-CAGCMGCCGCGGTAA-3' and 1000R 5'GGCCATGCACYWCYTCTC-3') of the 16S rRNA gene (Øvreås et al., 1997; Gantner et al., 2011; Takahashi et al., 2014). A quality check by gel electrophoresis, normalization, and pooling was performed on the amplicon libraries before independent sequencing of the bacterial and archaeal libraries on a MiSeq platform (MiSeqFGx, Illumina) using the v3 chemistry. This resulted in one archaeal and one bacterial 16S rRNA gene amplicon libraries (for detailed amplicon libraries preparation methods see section "Supplementary Material"). The raw data have been deposited in the Sequence Read Archive with BioProject number: PRJNA552490 (bacterial libraries) and PRJNA552540 (archaeal libraries).

Amplicon sequences were processed using QIIME2-2018.11 (Boylen et al., 2018). Bacterial and archaeal libraries were processed and analyzed in parallel applying the same plugin commands if not stated otherwise. Due to quality reasons only the bacterial and archaeal forward amplicon libraries (i.e., singleend) were used in this study. After the import of demultiplexed single-end fastq files via qiime import, primers were trimmed using qiime cutadapt trim-single. The QIIME2 plugin DADA2 (qiime dada2 denoise-single) was used for the detection and correction of Illumina-generated amplicon sequence data and to generate amplicon sequence variants (ASVs) using the following parameters for both libraries: $-p$-trim-left 0 and $-p$ trunc-len 250. Resulting bacterial and archaeal 16S rRNA gene representative ASV sequences were used to calculate phylogenetic ASV trees for subsequent analyses using the qiime phylogeny align-to-tree-mafft-fasttree plugin. Bacterial and archaeal primerspecific trained Naive Bayes taxonomic classifiers ${ }^{2}$, using the SILVA 132 release files ${ }^{3}$, were used to classify the representative ASV sequences (qiime feature-classifier classify-sklearn). Before subsequent analyses, the complete amplicon datasets, including all available Demospongiae, Hexactinellida, and seawater sample groups, where divided into additional sample group-specific datasets via the qiime feature-table filter-samples plugin.

The generated exact sequence variants, or amplicon sequence variants (i.e., ASVs), are used as substitute for the commonly used operational taxonomic units (OTUs) clusters of sequencing reads by applying the QIIME2 implemented DADA2 algorithm (Callahan et al., 2016; Nearing et al., 2018). The common pooling of sequences into OTUs limited the possibilities of deep sequencing by preventing fine-scale resolution. Therefore, we chose to generate ASVs instead of OTUs to achieve state-ofthe-art fine-scale community data and, in addition, to benefit from the error correction model applied by the DADA2 algorithm. In the following we will use the term feature, as introduced by QIIME2, when referring to the microbial ASVs (Boylen et al., 2018).

\section{Quantitative Real-Time PCR (qPCR)}

For quantification of the domain-level specific primers (eubacterial and archaeal 16S rRNA genes) we followed the protocol from Bayer et al. (2014). Briefly, 1:5 dilutions of purified PCR products were used as standards, and all standard dilutions

\footnotetext{
${ }^{2}$ https://docs.qiime2.org/2018.11/tutorials/feature-classifier/

${ }^{3}$ https://www.arb-silva.de/download/archive/qiime
} 
were prepared in aqueous tRNA solution (10 ng/ml) (SigmaAldrich, Schnelldorf, Germany). The DNA concentration of the highest starting solution of each standard dilution series as well as the diluted template DNAs was measured using the Qubit system (double stranded DNA, high sense kit, Thermo Fisher Scientific, Darmstadt, Germany). Quantitative PCRs were performed in a CFX Connect realtime detection system (Bio-Rad, Munich, Germany) using the SsoAdvanced ${ }^{\mathrm{TM}}$ Universal SYBR ${ }^{\circledR}$ Green Supermix (Bio-Rad) following the manufacturer's instructions. For both primer pairs, the reaction conditions previously tested (see Bayer et al., 2014) were used with one exception: the annealing/elongation temperature for the archaeal 16S rDNA gene assay was increased to $66^{\circ} \mathrm{C}$. For all $\mathrm{qPCR}$ assays, plate reads were taken at the end of each qPCR cycle. All template DNAs from sponges and seawater were tested in triplicates on each plate (technical replicates), whereas the corresponding standards were run in duplicates. The qPCR efficiency and gene copy numbers were calculated using the Bio-Rad CFX MANAGER ${ }^{\mathrm{TM}}$ software (version 3.1). Amplification of specific targets was confirmed by analyses of melt curves (in steps of $0.5^{\circ} \mathrm{C}$ for $5 \mathrm{~s}$, with temperatures ranging from 60 to $95^{\circ} \mathrm{C}$ ). Additionally, PCR product sizes were checked by electrophoresis on a $1.5 \%$ agarose gel (Peqlab now VWR, part of avantor) in 1x TAE buffer with $0.5 \%$ GelGreen $^{\mathrm{TM}}$ (Biotium, Hayward, CA, United States) for visualization.

\section{Bacterial and Archaeal Community Analyses}

Prokaryotic taxonomy tables from domain to species levels were created using the qiime taxa barplot plugin. A collective calculation of diversity metrics (both phylogenetic and nonphylogenetic) was applied on available datasets via the qiime diversity core-metrics-phylogenetic plugin, using the minimum sampling depth of each dataset for mandatory subsampling. The following alpha diversity indices were considered: Faith's phylogenetic diversity, observed features, Shannon diversity, and evenness. Visualization of beta diversity used the principal coordinates results, which were based on weighted uniFrac distances. Analyses of sample composition in the context of categorical metadata were performed with the qiime diversity beta-group-significance plugin (parameters: permanova and permdisp) again utilizing the weighted uniFrac distances. The ggpubr $\mathrm{R}$ package was used to calculate sample statistics and plot respective results (i.e., alpha diversity and qPCR bar charts, or PCoA plots $)^{4}$. Ternary plots were created using the Ternary plot maker web tool ${ }^{5}$. Finally, taxonomy bar plots and bacterial and archaeal features heatmaps were created using a custom R script and the ggplot2 package (Wickham, 2016). For heatmaps the respective feature abundance tables were sub-sampled for sponge samples only in order to avoid the bias introduced by abundant seawater features. The respective seawater samples were added subsequently before heatmap creation. Bacterial and archaeal feature Venn diagrams were

${ }^{4}$ https://cran.r-project.org/web/packages/ggpubr/

${ }^{5}$ https://www.ternaryplot.com/ created using mothur v.1.42.3 (Schloss et al., 2009). The complete QIIME2 pipeline and R script collection from the present study can be accessed online ${ }^{6}$.

\section{Archaeal Taxonomy Note}

The applied SILVA 132 database places the family Nitrosopumilaceae within the phylum Thaumarchaeota (class Nitrososphaeria; order Nitrosopumilales). However, a recent prokaryotic taxonomical reassessment using full genomes reorganized the taxonomy of the family Nitrosopumilaceae considerably (i.e., phylum Crenarchaeota; class Nitrososphaeria; order Nitrososphaerales) (Parks et al., 2018). In terms of reproducibility we decided to use the available SILVA 132 taxonomy without manual changes to certain taxa, such as the family Nitrosopumilaceae. However, the presented taxonomy might be a subject to change in upcoming SILVA releases.

\section{RESULTS}

\section{Deep-Sea Sponge Taxonomy}

Sponge taxonomic identifications were confirmed using a combination of gene markers, morphology, and spicule analyses. The 45 sponge specimens in this study belong to the two sponge classes Demospongiae and Hexactinellida. The Demospongiae group is composed of six taxa comprising the species Geodia vaubani Lévi and Lévi (1983), the novel species Halichondria sp. indet., Latrunculia sp. nov., the novel species Paratimea sp. indet., Penares turmericolor Sim-Smith and Kelly (2019), and Pleroma turbinatum Sollas (1888). The Hexactinellida group consists of seven taxa comprising the species Aphrocallistes beatrix Gray (1858), Bolosoma cyanae Tabachnick and Lévi (2004), Corbitella plagiariorum Reiswig and Kelly (2018), Leucopsacus distantus Tabachnick and Lévi (2004), Regadrella okinoseana Ijima (1896), Saccocalyx tetractinus Reiswig and Kelly (2018) and one novel species of Rossellidae that belongs to the Lanuginellinae subfamily (Table 1).

\section{Bacterial and Archaeal Features (Amplicon Sequencing)}

The sequencing of sponge-associated prokaryotic communities and additional seawater samples yielded 9120 bacterial and 1052 archaeal features in total, whereas the sequencing depth was relatively balanced with 1,960,245 bacterial and 2,090,246 archaeal sequence reads (Table 2). Excluding seawater samples, Hexactinellida exhibited the most bacterial features $(n=4357)$, compared to the Demospongiae $(n=2084)$ specimens. In contrast, the demosponge samples exhibited a higher archaeal feature count $(n=437)$, compared to the hexactinellids $(n=264)$. Finally, the archaeal seawater feature count $(n=791)$ was higher in comparison with the two sponge classes, whereas bacterial seawater features were almost similar to the hexactinellid counts $(n=4025)$ (Table 2).

${ }^{6}$ https://github.com/marinemoleco/So254Qiime2ASVs 

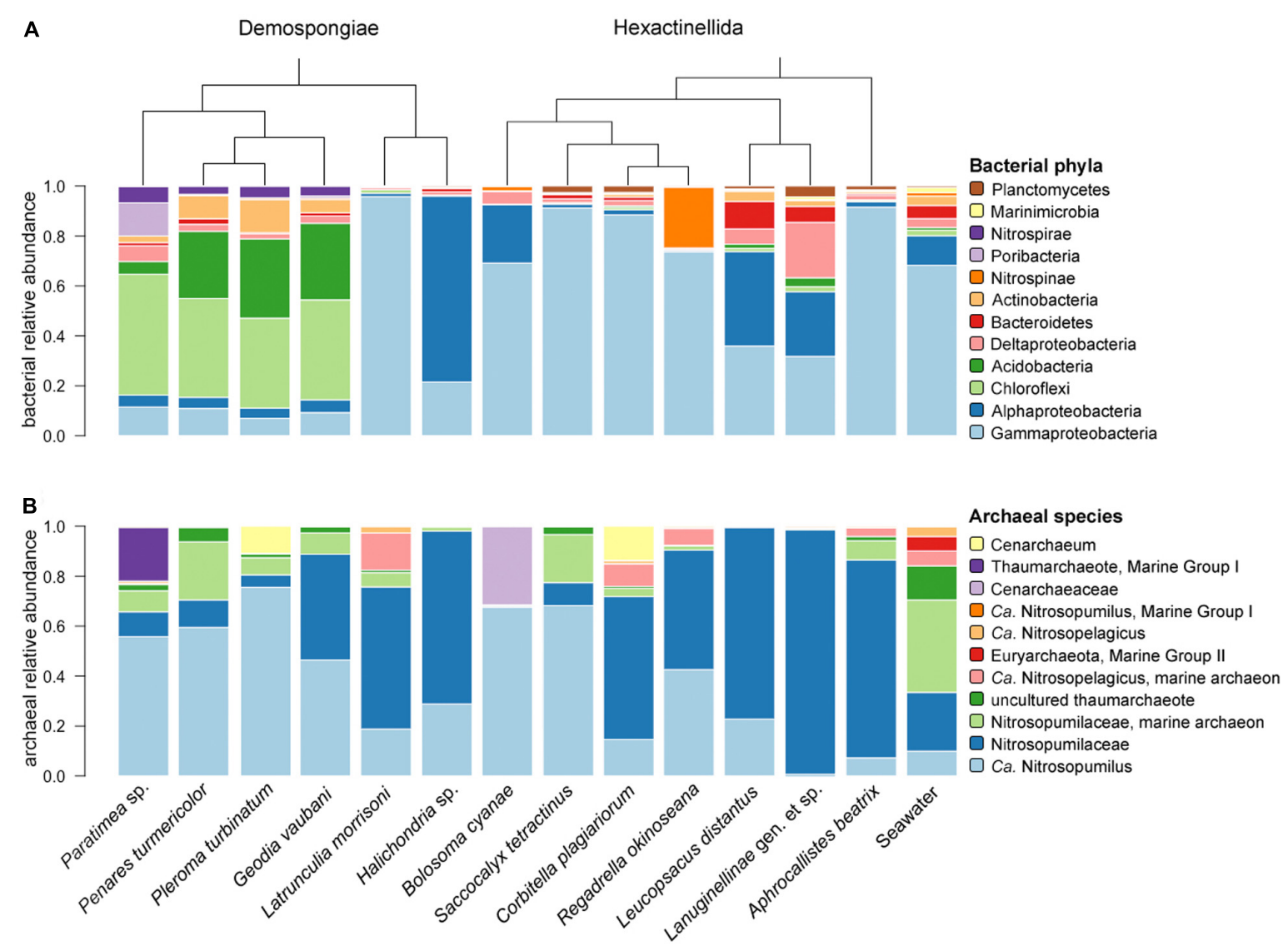

FIGURE 2 | Relative abundance of the most abundant bacterial phyla (A) and archaeal species (B) for all 13 sponges and seawater. The dendrogram is based on phylogenetic relationships between the sponge species. Samples are grouped by sponge class (Demospongiae, Hexactinellida).

TABLE 2 | Detailed bacterial and archaeal MiSeq library statistics, comprising the sequence data for (a) the whole dataset (i.e., Demospongiae, Hexactinellida, and seawater samples), (b) the Demospongiae subset, (c) the Hexactinellida subset, and (d) the seawater subset.

\begin{tabular}{lcc}
\hline Metric & Bacteria & Archaea \\
\hline Number of samples & 72 & 72 \\
Number of features & 9,102 & 1,052 \\
Total frequency & $1,960,245$ & $2,090,246$ \\
Demospongiae samples & 21 & 21 \\
Demospongiae features & 2,084 & 437 \\
Demospongiae frequency & 558,729 & 770,140 \\
Hexactinellida samples & 24 & 24 \\
Hexactinellida features & 4,357 & 264 \\
Hexactinellida frequency & 588,341 & 535,764 \\
Seawater samples & 27 & 27 \\
Seawater features & 4,025 & 791 \\
Seawater frequency & 813,175 & 784,342 \\
\hline
\end{tabular}

\section{Bacterial and Archaeal Taxonomy and Taxon Distribution}

In total, 44 bacterial phyla and four archaeal phyla (i.e., Thaumarchaeota, Euryarchaeota, Nanoarchaeota, and
Crenarchaeota) were present among all sponge and seawater samples. The demosponges Paratimea sp., P. turmericolor, $P$. turbinatum, and $G$. vaubani, contain Chloroflexi, Acidobacteria, Actinobacteria, and Nitrospirae as the most abundant bacterial phyla (Figure 2A). Surprisingly, the Paratimea sp. specimens possess a large fraction of poribacterial symbionts (Figure 2A). The Hexactinellida contain bacterial phyla, such as Proteobacteria (Delta-), Bacteroidetes, Nitrospinae, or Planctomycetes, which are relatively more abundant than in the investigated demosponge specimens (Figure 2A).

Due to the Thaumarchaeota dominance (92-100\% relative abundance among all sample groups - see Supplementary Table S2) and the overall low archaeal feature richness (compared to the bacterial community - see Supplementary Figure S2), we considered the archaeal species composition as the relevant taxonomic level in our following community description throughout the present study. This is in contrast to the common phylum composition approach that has been used to describe sponge-associated bacterial communities. At species level a total of 76 archaeal taxa, compared to 1774 bacterial taxa, could be designated to all features present in the sponge and seawater samples. Among those 76 archaeal taxa the subset comprising the most abundant archaea was composed of 


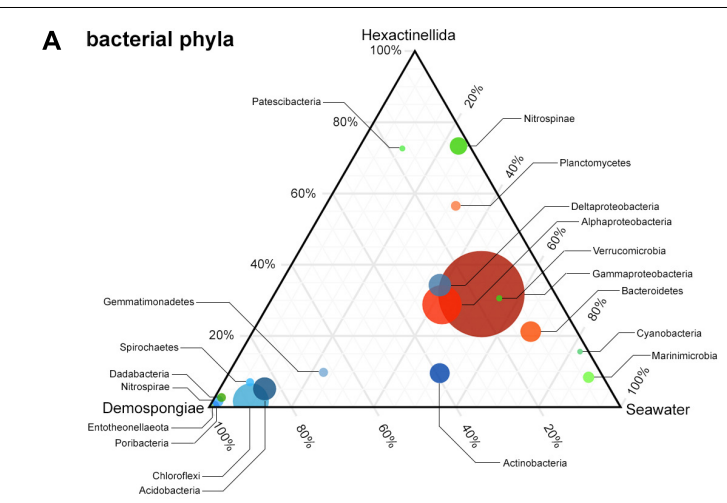

B bacterial genera

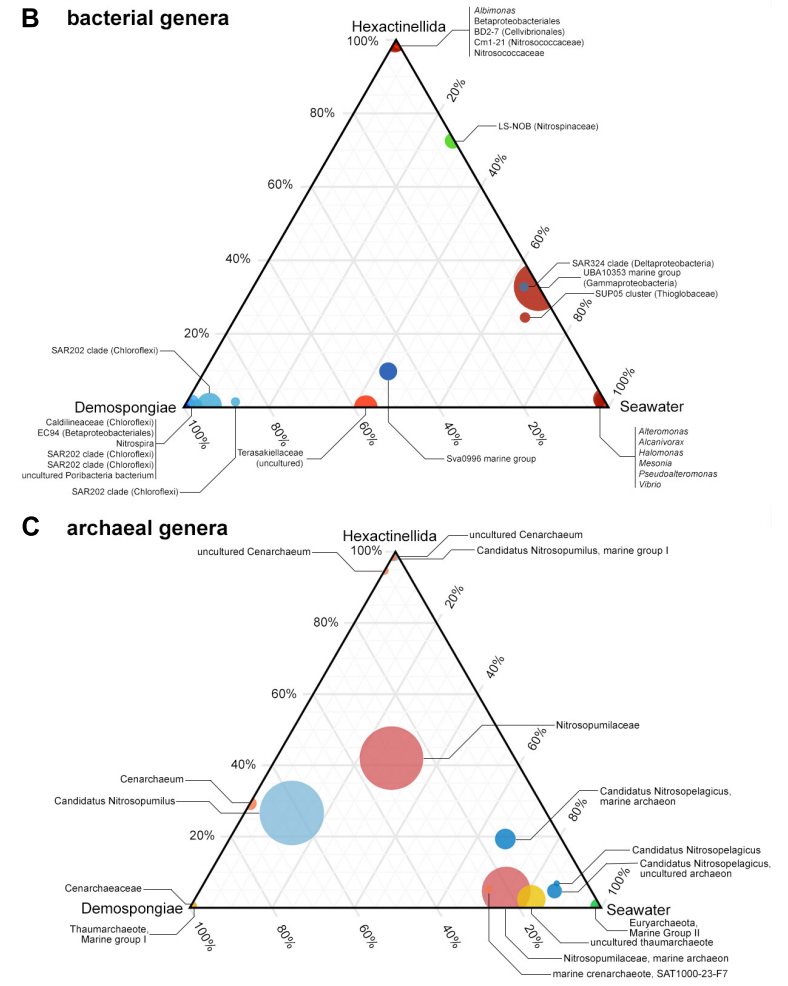

FIGURE 3 | Ternary plots showing the distribution of the most abundant taxa of bacterial phyla (A), bacterial genera (B), and archaeal genera (C) among the pooled Demospongiae, Hexactinellida, and seawater samples. Circle size is indicative of the relative abundance of these phyla.

almost only thaumarchaeotes, except one euryarchaeotal taxon (Thermoplasmata, Marine Group II) (Figure 2B). In addition, all top thaumarchaeotes belong to the family Nitrosopumilaceae (Figure 2B), which could be further identified as several Candidatus taxa, such as Nitrosopumilus or Nitrosopelagicus.

Ternary plots were used to examine the distributions of the bacterial and archaeal most abundant taxa among the pooled demosponges, hexactinellids, and seawater samples. As indicated by the ternary plots, certain bacterial phyla are almost exclusive to Demospongiae; such as Acidobacteria, Chloroflexi, Dadabacteria, Nitrospirae, Spirochaetes, Entotheonellaeota, or Poribacteria (Figure 3A). On the contrary, there is no evidence that the present hexactinellids possess an exclusive phylum. However,
Patescibacteria and Nitrospinae seem to be more related to this sponge class as opposed to demosponges or the surrounding seawater. In addition, Marinimicrobia, Cyanobacteria, and Bacteroidetes exhibit a preference for the present seawater samples (Figure 3A). Finally, the group of several abundant proteobacterial classes, and Verrucomicrobia, show an almost even distribution among all three biotopes, however, with a clear tendency for the seawater samples.

On genus level there are some demosponge- (e.g., Caldilineaceae, EC94, SAR202 clade, and Poribacteria) or hexactinellid- (e.g., Albimonas, Betaproteobacteriales, Nitrosococcaceae, BD2-7, and Cm1-21) specific taxa that seem to be exclusive for one of the two sponge classes (Figure 3B). In addition, the seawater samples possess certain exclusive genera, such as Alteromonas, Halomonas, Pseudoalteromonas, or Vibrio.

Similar to the bacterial genera ternary plot, the most abundant archaeal assemblages can be grouped into either Demospongiae-, Hexactinellida-, or seawater-specific taxa. Here, certain taxa are highly specific to one of the available main groups (Figure 3C). For instance, the single euryarchaeotal taxon (Marine Group II) is only present in the seawater samples, whereas several Nitrosopumilaceae-related taxa are highly characteristic for one of the two sponge classes. Moreover, all three abundant Candidatus Nitrosopelagicus taxa have a strong preference for the seawater samples (Figure 3C). On the contrary, the Candidatus Nitrosopumilus taxa show either a tendency for demosponges and seawater samples or are unique to the Hexactinellida. Finally, a large group composed of not further classified Nitrosopumilaceae features is present almost at the center between all main biotopes, hinting to an even distribution of further Nitrosopumilaceae-related features among the three biotopes (Figure 3C).

\section{Alpha Diversity Analysis}

Rarefied abundance tables, generated using the individual sample read counts and feature assemblages, were used to calculate the mean bacterial and archaeal feature diversity at a local scale (i.e., alpha diversity indices for demosponges, hexactinellids, and seawater groups). Alpha diversity analyses of the bacterial communities revealed that all four indices (i.e., Faith's PD,

TABLE 3 | Bacterial and Archaeal alpha diversity for Demonspongiae, Hexactinellida, and seawater.

\begin{tabular}{|c|c|c|c|c|c|c|c|}
\hline & & \multicolumn{2}{|c|}{ Demospongiae } & \multicolumn{2}{|c|}{ Hexactinellida } & \multicolumn{2}{|c|}{ Seawater } \\
\hline & & $\mathbf{H}$ & $p$-value & $\mathbf{H}$ & $p$-value & $\mathbf{H}$ & $p$-value \\
\hline \multirow[t]{2}{*}{ Faith's PD } & Bacteria & 14.37 & 0.013 & 18.17 & 0.006 & 15.33 & 0.053 \\
\hline & Archaea & 6.09 & 0.298 & 4.50 & 0.480 & 11.93 & 0.155 \\
\hline \multirow[t]{2}{*}{ Features } & Bacteria & 18.07 & 0.003 & 18.14 & 0.006 & 14.10 & 0.079 \\
\hline & Archaea & 5.43 & 0.365 & 4.00 & 0.677 & 15.90 & 0.044 \\
\hline \multirow[t]{2}{*}{ Shannon } & Bacteria & 18.97 & 0.002 & 18.67 & 0.005 & 19.96 & 0.010 \\
\hline & Archaea & 3.71 & 0.592 & 6.29 & 0.391 & 21.19 & 0.007 \\
\hline \multirow[t]{2}{*}{ Evenness } & Bacteria & 18.48 & 0.002 & 19.11 & 0.004 & 19.15 & 0.014 \\
\hline & Archaea & 4.22 & 0.518 & 6.57 & 0.363 & 17.40 & 0.026 \\
\hline
\end{tabular}

Significant $p$ values are highlighted in bold. 
observed features, Shannon diversity, and evenness) were significantly different within both sponge classes (Table 3). In contrast, the archaeal feature assemblages showed no significant alpha diversity differences between the species belonging to the two sponge classes. Seawater samples apparently deviated from that overall pattern by exhibiting almost no significant differences for the two present richness indices, except the observed archaeal features $(p=0.044)$, whereas Shannon diversity and evenness showed significant differences among the seawater samples for both prokaryotic domains (Table 3). In addition, the comparisons between the three biotopes showed significant differences among all available alpha diversity indices for bacteria and archaea (Supplementary Figure S2). However, significant $p$-values were lower for the archaeal features compared to the bacterial $p$-values. Moreover, Faith's PD and observed feature values for bacteria and archaea were highest within the seawater samples, followed by demosponges and hexactinellids (Supplementary Figure S2). The same pattern was visible in the bacterial and archaeal Shannon and evenness indices, where the spread was much higher in the sponge related samples compared to the richness indices (Supplementary Figure S2).

\section{Beta Diversity Analysis}

The same rarefied abundance tables that were used in the alpha diversity analyses were again utilized to look at several beta diversity aspects (i.e., community differences between samples). First, the bacterial and archaeal abundance and composition information was employed to investigate the differences between the Demospongiae, Hexactinellida, and seawater samples (Figures 4A,B). Regarding the bacterial community, two main groups are visibly separated by the first axis (34\% variance explained) (Figure 4A). The larger

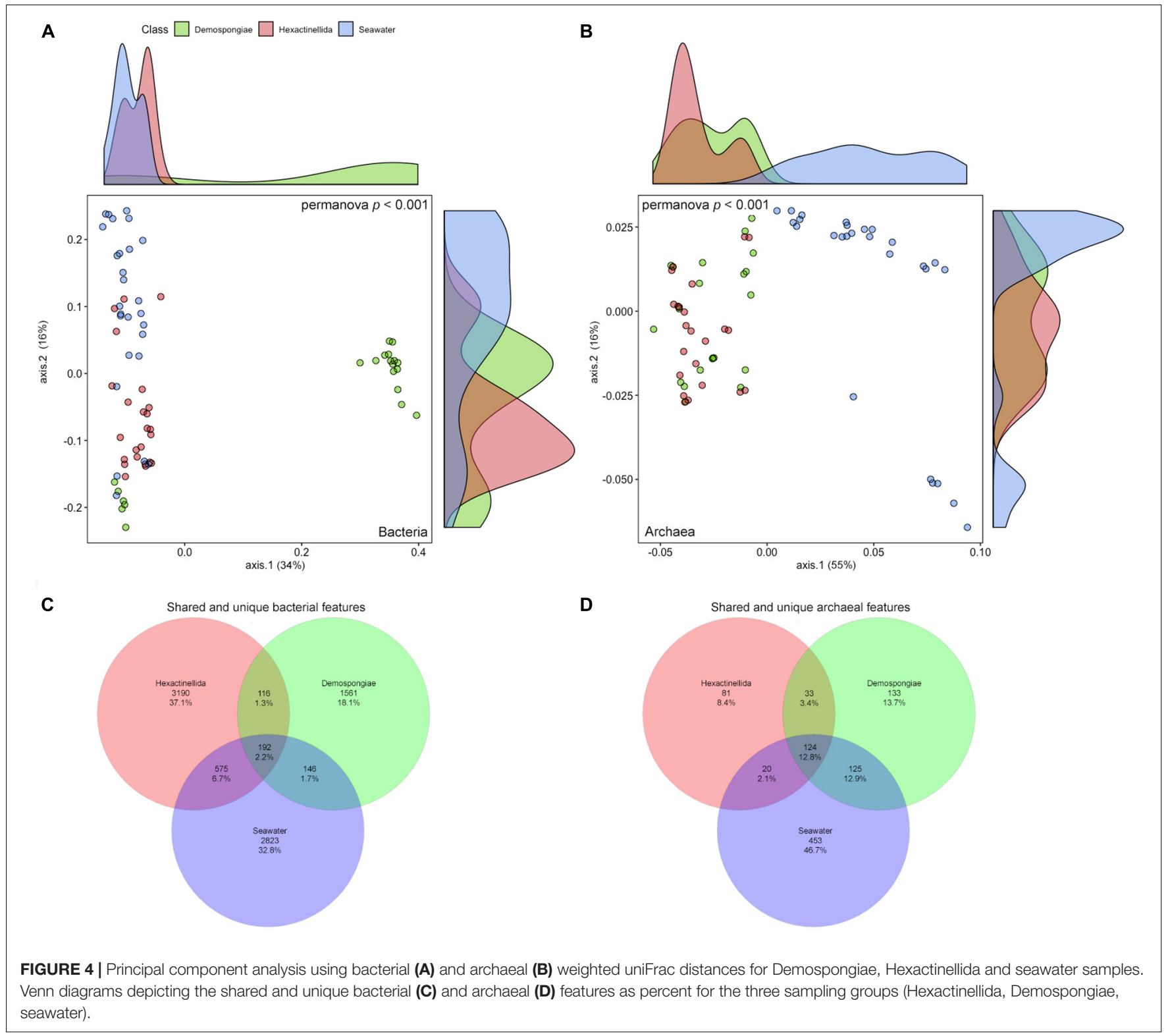


group is composed of all Hexactinellida, seawater, and a Demospongiae subset, whereas the second group exclusively consists of demosponges. However, the larger group also exhibits a relatively distinct separation between the seawater, Hexactinellida, and Demospongiae samples. In this group, the second axis separates the seawater- and Demospongiae subsets, while the Hexactinellida prevailing subsets are in-between these two distinct groups ( $16 \%$ variance explained). Nevertheless, a few overlaps between these biotopes exist (Figure 4A). Comparative statistics showed that the group identity has a significant effect on the community composition $(p<0.001)$, while the variances were homogeneous $(p=0.083)$ (Figure 4A and Table 4).

In case of the archaeal feature composition and abundance, the first axis clearly separates the sponge samples from the seawater samples (55\% variance explained) (Figure 4B). Furthermore, seawater samples are then subset by the second axis (16\% variance explained) into one large and one small group. The smaller group is comprised of seawater samples from ROV station 13 (Otago-Canterbury slope) and station 14 (Christchurch slope), which are both located on the continental slope of the South Island within the subtropical front separating the water masses of the South Pacific Subtropical Gyre to the north from the Subantarctic Water Ring to the south (Carter, 2001; Figure 1 and Supplementary Figure S3, Table 1). In comparison, the sponge samples exhibit no clear separation into Demospongiae and Hexactinellida specimens, hence forming a heterogeneous group apart from the seawater samples (Figure 4B). However, overall the archaeal composition was still significantly affected by group identity $(p<0.001)$, further supported by homogeneously dispersed groups $(p=0.895)$ (Figure 4B and Table 4).

TABLE 4 | Community permanova and permdisp statistics, comprising the sequence data for (a) the whole dataset (i.e., Demospongiae, Hexactinellida, and seawater samples), (b) the Demospongiae subset, (c) the Hexactinellida subset, and (d) the seawater subset.

\begin{tabular}{llcccc}
\hline Group & Sample size & Groups & Test statistic & p-value \\
\hline Bacteria & Group permanova & 72 & 3 & 15.27 & $\mathbf{0 . 0 0 1}$ \\
& Group permdisp & 72 & 3 & 2.53 & 0.083 \\
Demo permanova & 21 & 6 & 40.99 & $\mathbf{0 . 0 0 1}$ \\
Demo permdisp & 21 & 6 & 30.09 & $\mathbf{0 . 0 1 3}$ \\
Hexac permanova & 24 & 7 & 7.74 & $\mathbf{0 . 0 0 1}$ \\
Hexac permdisp & 24 & 7 & 4.50 & $\mathbf{0 . 0 0 2}$ \\
SW permanova & 27 & 9 & 7.35 & $\mathbf{0 . 0 0 1}$ \\
SW permdisp & 27 & 9 & 0.58 & 0.451 \\
Archaea & Group permanova & 72 & 3 & 32.52 & $\mathbf{0 . 0 0 1}$ \\
Group permdisp & 72 & 3 & 0.09 & 0.895 \\
Demo permanova & 21 & 6 & 1.22 & 0.203 \\
Demo permdisp & 21 & 6 & 1.82 & 0.19 \\
Hexac permanova & 24 & 7 & 1.28 & 0.106 \\
Hexac permdisp & 24 & 7 & 0.56 & 0.496 \\
SW permanova & 27 & 9 & 20.99 & $\mathbf{0 . 0 0 1}$ \\
SW permdisp & 27 & 9 & 0.47 & 0.235 \\
\hline
\end{tabular}

Significant $p$ values are highlighted in bold.
Finally, biotope-specific subsets (i.e., Demospongiae, Hexactinellida, and seawater) revealed that the demosponge and/or hexactinellid host-identity has a significant effect on the bacterial community composition $(p<0.001$ for both sponge classes) (Supplementary Figures S3A,C and Table 4), whereas no significant effect of sponge identity could be observed for the archaeal data $(p=0.203$ and $p=0.106$ for demosponges and hexactinellids, respectively) (Supplementary Figures S3B,D and Table 4). In comparison, sampling location has a significant effect on the bacterial and archaeal community composition of the seawater samples (Supplementary Figures S3E,F and Table 4).

\section{Bacterial and Archaeal Feature Distribution and Abundance}

Venn diagrams visualized the shared and unique bacterial and archaeal features for the three sampling groups (Figures 4C,D). Overall, the percentage of shared bacterial features among all three groups is low and consequently each of the sample groups exhibits a large share of unique features $(37.1,18.1$, and $32.8 \%$ for Hexactinellida, Demospongiae, and seawater, respectively) (Figure 4C). Similarly, for the archaeal features, the pooled seawater samples hold the largest share of the archaeal features $(46.7 \%)$ compared to the demosponges $(13.7 \%)$ and hexactinellids (8.4\%) (Figure 4D). Moreover, some shared features (i.e., $12.9 \%$ for seawater/Demospongiae, and $12.8 \%$ for seawater/Demospongiae/Hexactinellida) exceed the Hexactinellida-unique features. Despite the large fraction of seawater-unique features the amount of shared features between Hexactinellida and seawater is low (2.1\%).

We plotted the most abundant bacterial and archaeal features within the sponge subset as separated relative abundance heatmaps (Figure 5). The bacterial heatmap reveals that certain features are either highly host-species specific (e.g., Caldilineaceae gen. et sp. indet., SAR202 clade, Nitrospira sp., Pseudohongiella sp., Nitrospina sp., Roseobacter clade NAC11-7, EC94, Cellvibrionales BD27 , or Nitrosococcaceae) or predominant in the respective sponge classes (Demospongiae: Dadabacteriales, Nitrospira sp.; Hexactinellida: UBA10353 marine group). Overall, the distribution among the hexactinellid samples appears to be more scattered compared to the demosponge samples. Finally, seawater does not possess any of the sponge-specific bacterial features in large abundances and across all samples from the same location (Figure 5). The archaeal heatmap revealed that individual sponges possess single highly abundant features, which all belong to different Nitrosopumilaceae taxa (Figure 5). Contrary to the host-species specific distribution of the bacteria, sponge-associated archaeal symbionts are apparently individual-specific rather than host-specific. In contrast, seawater samples do not possess these singular highly abundant features. Instead, those samples rather exhibit location-specific feature distribution patterns (Figure 5). This corresponds with the archaeal ordination plots (Figure 4 and Supplementary Figure S3) and the respective archaeal 


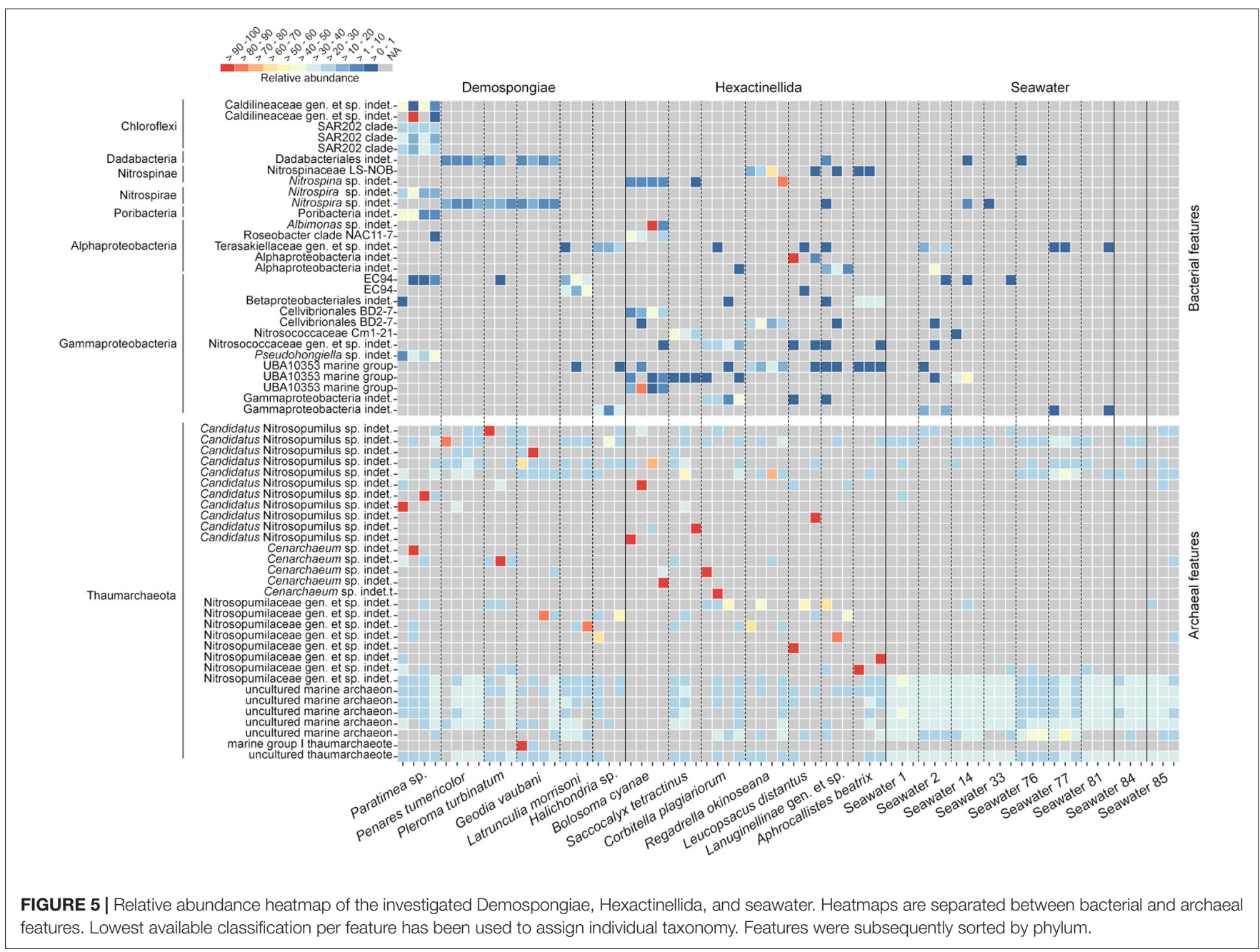

community statistics (Table 4). Concerning the spongeassociated archaeal features, there seems to be a tendency that those singular abundant archaea predominantly belong to certain taxa (i.e., Candidatus Nitrosopumilus or Cenarchaeum).

\section{Quantitative Assignment of Sponge-Associated Bacterial and Archaeal 16S rRNA Genes}

For both qPCR assays the published reaction conditions (Bayer et al., 2014) were re-tested with respect to primer concentration, annealing, and elongation temperature and time. Both assays showed good in silico coverage and specificity and showed qPCR efficiencies between 95 and 105\% with external standards according to MIQE guidelines (Bustin et al., 2009). One exception was that the annealing/elongation temperature for the archaeal assay was increased to $66^{\circ} \mathrm{C}$ for specificity reasons but without reaction efficiencies loss (Supplementary Table S3). All qPCR results are expressed as gene copy numbers per microgram genomic DNA. The $16 \mathrm{~S}$ rRNA gene copy numbers as estimated by qPCR with domain-specific primers for the investigated sponges are reported as follows (Supplementary Table S4). Bacterial 16S rRNA gene copy numbers ranged from $5.05 \times 10^{10} \pm 1.54 \times 10^{10}$ to $2.53 \times 10^{11} \pm 2.55 \times 10^{10}$ in hexactinellid sponges, to $5.62 \times 10^{10} \pm 4.79 \times 10^{9}$ to $1.81 \times 10^{11} \pm 3.46 \times 10^{10}$ in Demospongiae. Archaeal 16S rRNA gene copy numbers varied from $2.01 \times 10^{9} \pm 1.23 \times 10^{8}$ to $2.71 \times 10^{11} \pm 2.57 \times 10^{10}$ in hexactinellid sponges, to $3.09 \times 10^{8} \pm 1.29 \times 10^{7}$ to $3.24 \times 10^{10} \pm 1.73 \times 10^{9}$ in Demospongiae (Supplementary Figure S4 and Supplementary Table S4). As the fraction of host DNA within total extracted DNA potentially varies in every sample, we further calculated the ratios of bacteria and archaeal 16S rRNA gene copy numbers. We found that the prokaryotic consortia of hexactinellid sponges $B$. cyanae and $R$. okinoseana seem to have a high proportion of associated Archaea (BAC: $\mathrm{ARCH}$ ratios between 0.3 and 3.8), whereas $C$. plagiariorum deviates from that (BAC: ARCH ratios between 14.6 and 16.6). Demospongiae samples showed a higher proportion of Bacteria on average compared to Archaea (BAC: ARCH ratios between 4.0 and 21.9), with one apparent exception, which is L. morrisoni (BAC: ARCH ratios between 171.1 and 322.1) (Supplementary Table S4). Finally, the conversion of 16S rRNA gene copy numbers into BAC: ARCH ratios showed that Archaea, 


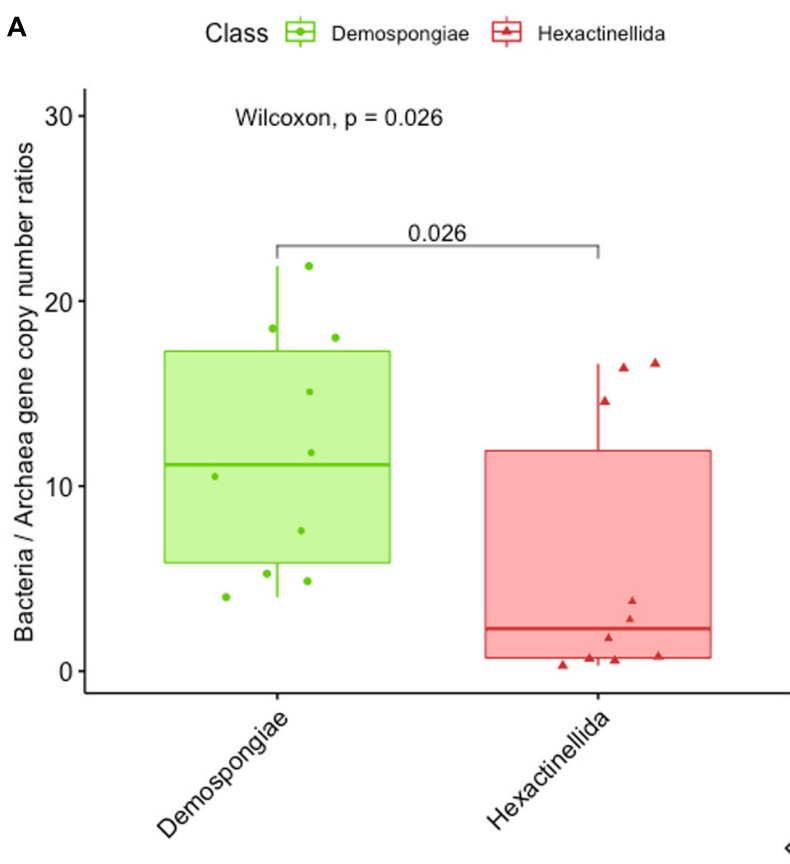

Sponge class
B Class Demospongiae

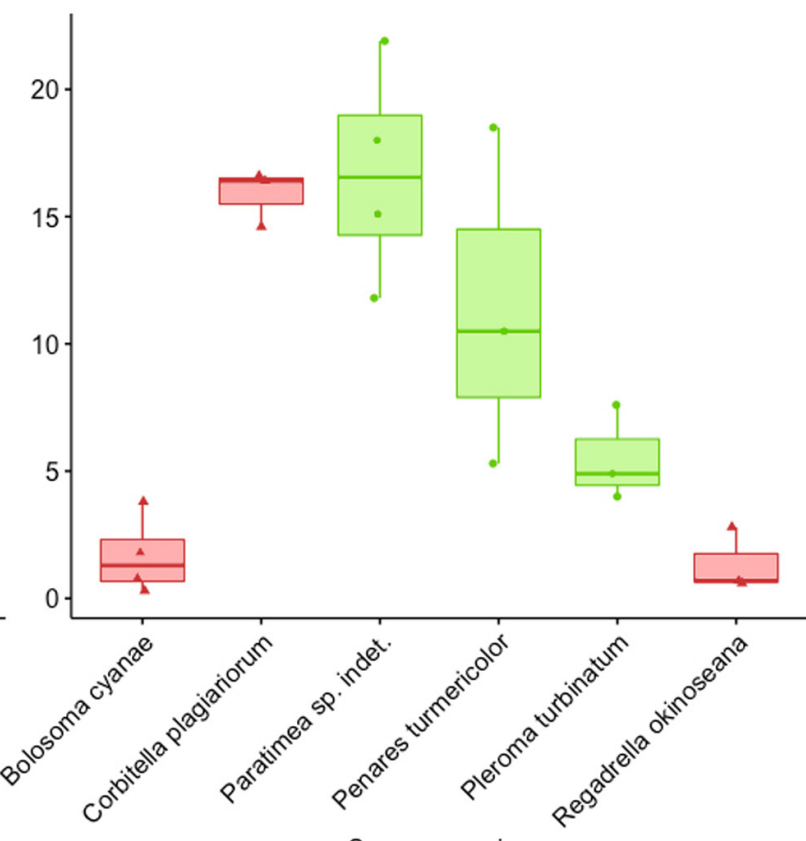

Sponge species

FIGURE 6 | Results of the qPCR experiments for bacterial and archaeal abundance presented as ratio of bacteria and archaea gene copy numbers. (A) Representing the overall average for Demospongiae and Hexactinellida. (B) Showing the ratio of bacteria and archaea gene copy numbers for three species of Demospongiae and Hexactinellida, respectively.

compared to the bacterial copy numbers, are significantly ( $p=0.026)$ more abundant in hexactinellids than in demosponges (Figure 6A). However, a closer look at the individual sponge species revealed one exception from that initial observation (Figure 6B; C. plagiariorum with a BAC: ARC ratio between 14.6 and 16.6). A potential limitation of using the bacteria vs. archaeal ratio could be a possible bias in primer amplification, because of the use of two different 16S rRNA gene primer pairs.

\section{DISCUSSION}

\section{Bacterial Communities in Deep-Sea Demosponges and Hexactinellids}

Since the beginning of sponge microbiome research (Vacelet, 1975; Vacelet and Donadey, 1977) the emphasis was placed on sponges from shallow-water marine habitats while sponges from cold-water and/or deep-sea locations are still understudied. Here, we explored the microbial community composition of demosponges and hexactinellids from the South Pacific by constructing independent bacterial and archaeal partial $16 \mathrm{~S}$ rRNA gene libraries. While collection of sponges during the SO254 expedition included only deep-water specimens, analyses of microbiota patterns between deep-water and shallow-water sponges relied on literature data for shallow-water microbiota data (e.g., Thomas et al., 2016; Moitinho-Silva et al., 2017b).
The six demosponges showed a microbial signature similar to that of shallow-water demosponges with the phyla Proteobacteria (Gamma-, Alpha-, and Delta-), Chloroflexi, Acidobacteria, Bacteroidetes, Nitrospinae, Nitrospirae, and Poribacteria being most abundant. One apparent difference to shallow-water sponges is the general lack or low abundance of members of the phylum Cyanobacteria, which are typically more abundant in shallow-water sponges (e.g., Erwin and Thacker, 2008; Bayer et al., 2014; Burgsdorf et al., 2014; Thomas et al., 2016). Given their involvement in photosynthesis it is not surprising that the present deep-sea sponges contain reduced numbers of this phototrophic bacterial phylum. The highly sponge-specific phylum Poribacteria appears to be underrepresented in sponges from deep-sea or cold habitats in the present and previous studies (Jackson et al., 2013; Rodríguez-Marconi et al., 2015; Cárdenas et al., 2018; Steinert et al., 2019). Noteworthy, we identified one sponge species (Paratimea sp.) with abundant poribacterial features. The overall phylum composition of this sponge matches the typical taxon composition of high microbial abundance (HMA) sponges as defined by MoitinhoSilva et al. (2017b). Also, three more demosponges in this study (i.e., P. turmericolor, P. turbinatum, and G. vaubani) exhibited these HMA indicator taxa, although Poribacteria were lacking. The two remaining demosponge species (i.e., Latrunculia sp. nov. and Halichondria sp. indet.), display microbiome characteristics typical of LMA sponges (see Figure 2). In summary, with respect to bacterial community composition and 
HMA/LMA status, the demosponges from this remote deepsea location largely resemble those of shallow-water collections (Thomas et al., 2016).

Regarding the seven hexactinellid species in the present study there is no literature available for comparisons with other hexactinellids from similar or different habitats. Overall, Gammaproteobacteria dominated the hexactinellid species. While Gammaproteobacteria are common predominant members in sponge bacterial communities, usually those demosponge-related communities exhibit additional dominant taxa regardless of climate zone or sampling depth (e.g., Kennedy et al., 2014; Thomas et al., 2016; Cárdenas et al., 2018; Steinert et al., 2019). Two species, i.e., Lanuginellinae gen. et sp. and L. distantus, also possess abundant Proteobacteria (Alphaand Delta-), Bacteroidetes, and Chloroflexi, thus resembling a bacterial community pattern commonly found in demosponges.

When comparing the two sponge classes, evenness and diversity were indeed lower in hexactinellids compared to demosponges. Besides these alpha-diversity metrics, bacterial community composition and diversity differences are prominent throughout all present analyses. For instance, at least some demosponges possess specific phyla, like the HMA indicators, whereas hexactinellids resemble LMA sponges regarding their bacterial taxon composition. Secondly, demosponges and hexactinellids do not overlap in the ordination analyses, hence hexactinellids possess a rather class-specific microbiota. This is especially apparent when comparing the feature distribution between LMA-like demosponges and hexactinellids. The Hexactinellida-associated features exhibit a more heterogeneous distribution. Hexactinellida are usually cold water/deep-sea sponges (van Soest et al., 2012). Such habitats imply lower food availability and therefore different metabolic functions in species of this sponge class. Moreover, glass sponges are clearly distinct to other sponge classes by body shape and features such as tissue and spicules (van Soest et al., 2012). We assume that these morphological differences also affect the microbiota composition of this class. Sponges are holobionts (Webster and Thomas, 2016); hence the symbiotic bacterial relationships are adapted to the Pita et al. (2018) host-ecosystem, which could be visible as discernable differences between demosponges and hexactinellid bacterial communities.

Demospongiae and Hexactinellida also share some common sponge-bacteria related characteristics, such as their noticeable difference to seawater samples (e.g., Lee et al., 2010; Taylor et al., 2013; Steinert et al., 2016; Cleary et al., 2018; Helber et al., 2019), which is present in the ordination plots or manifested in the alpha- and beta-diversity results. Especially apparent is the Hexactinellida-related host-specificity (see Supplementary Figure S3C), which is equally consistent in their demosponge counterparts (see Supplementary Figure S3A). Host-specificity is a common feature of the sponge-microbiota relationship, but so far only observed and described in depth for demosponges (Pita et al., 2013; Easson and Thacker, 2014; Thomas et al., 2016; Steinert et al., 2017, 2019). This pattern seems to be similar in hexactinellids, implying analogous bacterial community acquisition and maintenance processes as in their demosponge counterparts.

\section{Archaeal Communities in Deep-Sea Demosponges and Hexactinellids}

At high taxonomic archaeal ranks (i.e., from phylum to family level), both Demospongiae and Hexactinellida are dominated or even exclusively inhabited by the phylum Thaumarchaeota, and more specifically, several genera and species from the family Nitrosopumilaceae. The ecologically important candidatus family Nitrosopumilaceae forms a monophyletic group in the candidatus order Nitrosopumilales based on 16S rRNA and candidatus amoA (encoding for the $\alpha$-subunit of ammonia monooxygenase) gene sequence analyses (Torre et al., 2016). The Nitrosopumilaceae comprises five genera, three of which were present in our sponges, namely: Candidatus Nitrosopelagicus, Candidatus Nitrosopumilus, and Candidatus Cenarchaeum. Nitrosopumilaceae grow chemolithoautotrophically by acquiring energy from ammonia oxidation and using $\mathrm{CO}_{2}$ as carbon source. Additionally, some species can utilize urea as a source of ammonia for energy and growth (Torre et al., 2016). Marine demosponges are known hosts of symbiotic thaumarchaeotal members, but the understanding of their functional relationship is still lacking and mostly relies on circumstantial evidence (e.g., Kennedy et al., 2014; Feng et al., 2016, 2018; That et al., 2018; Moeller et al., 2019).

Different nitrogen cycling processes, such as nitrification, denitrification, and anaerobic ammonium oxidation have been observed in different demosponge species (e.g., Bayer et al., 2008; Hoffmann et al., 2009; Schläppy et al., 2010; Radax et al., 2012). Ammonia-oxidizing archaea (AOA) (i.e., thaumarchaeotes) are often abundant and diverse members of the sponge microbiota. AOA have even been detected in sponge larvae indicating vertical transmission and/or early environmental acquisition (Sharp et al., 2007; Steger et al., 2008; Schmitt et al., 2012). Transcription and translation of important functional genes, like the amoA gene of thaumarchaeotes, has been observed in different demosponge species (e.g., Bayer et al., 2008; Liu et al., 2012; Radax et al., 2012; Moitinho-Silva et al., 2017a). More complete genomic information about members of the phylum Thaumarchaeota, or more specifically the family Nitrosopumilaceae, has shed light on the metabolic potential and functional relationships of this putatively important sponge-symbiotic archaeal group. So far, genomic information comprising different taxa within the family Nitrosopumilaceae is available from three demosponges (Axinella mexicana, Cymbastela concentrica, Ianthella basta), and even one hexactinellid (Lophophysema eversa) (Hallam et al., 2006; Tian et al., 2016; Moitinho-Silva et al., 2017a; Moeller et al., 2019). Given the involvement of the Nitrosopumilaceae family in sponge-related nitrogen cycling processes, it can be assumed that thaumarchaeotal ammonia oxidation is a key functional process in deep-sea demosponges and hexactinellids alike.

\section{Nitrosopumilaceae Are Sponge- but Not Sponge Species-Specific}

We performed a high resolution screening of prokaryotic communities in demosponges and hexactinellids to look at the broad archaeal community in greater detail, and to directly compare community patterns and absolute abundances between 
bacterial and archaeal domains. Therefore, we constructed two independent bacterial and archaeal 16S rRNA gene libraries and quantitative real-time PCR in this study.

The difference between bacterial and archaeal communities is most apparent in sponge host-specificity, either at sponge class rank and/or at sponge species level (Figures 4A,B and Supplementary Figures S4A,B). Generally, bacterial demosponge-associated communities exhibit stable host-species specific patterns, which are affected by sponge-host identity and even sponge phylogeny (Easson and Thacker, 2014; Thomas et al., 2016; Steinert et al., 2017). The present archaeal communities do not show any distinct host-relatedness among all sponge species in both classes. Another difference between bacterial and archaeal community relationships is the feature distribution. Unique Nitrosopumilaceae features are randomly distributed among individual specimens and sponge taxa (Figure 5). In contrast, dominant sponge-associated bacteria often displayed sponge species-specific distribution patterns that are generally explained by particular metabolically and functional host-symbiont relationships (Fan et al., 2012; Ribes et al., 2012; Thomas et al., 2016). The present archaeal feature distribution indicates that a random symbiont acquisition process is present among all sponges, which is independent of host phylogeny. Nevertheless, we assume that the latter processes are sponge-specific due to the evident differences between sponge- and seawater-associated archaeal communities (Figures 4B, 5).

In summary, Nitrosopumilaceae acquisition seems to happen randomly across all sponge samples. This implies functional redundancy of the symbiont's key functional processes within the deep-sea sponge-associated genera of the family Nitrosopumilaceae. Functional redundancy, or evolutionary equivalence, has been hypothesized and observed also for sponge-associated bacteria, but usually at higher taxonomic ranks (Fan et al., 2012; Ribes et al., 2012; Thomas et al., 2016).

\section{Bacterial and Archaeal Abundance}

Finally, quantitative real-time PCR using both bacterial and archaeal universal 16S rRNA gene primers support the overall results. Although $\mathrm{qPCR}$ is a very sensitive method to assess microbial quantities, there are technical aspects that need to be considered. For example, the amplification of free DNA in sea water and sponge samples cannot be excluded and numbers might be overestimated. One explanation for the relatively high values could be the detection of dead material deposits from the upper water column in all three biotopes (i.e., Demospongiae, Hexactinellida, and seawater). As environmental microbes may encode for more than one $16 \mathrm{~S}$ rRNA gene per genome, we express microbial abundances as gene copy number per microgram genomic DNA and compare it to literature (Bayer et al., 2014). Bacterial gene copy numbers were within the range found in shallow-water HMA demosponges (Bayer et al., 2014) and no significant difference was found comparing demosponges and hexactinellids from the deep sea (this study). Archaeal gene copy numbers detected in both deep-sea demosponges and hexactinellids were up to three orders of magnitude higher than in shallowwater counterparts (see Bayer et al., 2014), highlighting the importance of archaeal symbionts for deep-sea sponges in general. Since cold water carries more $\mathrm{CO}_{2}$ than warmer water (Garrison, 2009) the physiological evidence for archaea using $\mathrm{CO}_{2}$ as a carbon source (Wuchter et al., 2004; Könneke et al., 2014) might explain their higher abundance in deepsea waters and sponges where ammonium for nitrification purposes might not be limited. Altogether, this suggests a major role of AOA in deep-sea sponge metabolism (in particular for the hexactinellid species), by providing additional metabolites via chemoautotrophy, similar to what diatoms or cyanobacteria contribute via photoautotrophy in shallowwater sponges (see Feng and Li, 2019 and references within). Hence, future (meta)-omic's studies should explore if deep-water sponge microbiomes also contain chemoautotrophic bacteria, which could provide further resources to the host sponges in addition to the AOA.

\section{CONCLUSION}

We investigated bacterial and archaeal communities from two sponge classes using independent 16S rRNA gene libraries and quantitative real-time PCR. With regard to bacteria, both demosponges and hexactinellids exhibit community characteristics similar to shallow-water sponges, including the presence of typical sponge symbiont taxa as well as host species-specific microbiomes for all sponge species investigated. In contrast, the archaeal community was taxonomically highly homogeneous and could only be resolved from the Nitrosopumilaceae family level on downward (i.e., from family to individual ASVs). However, the quantitative information hints at three orders higher archaeal gene copy numbers between shallow water and the present deep-water sponges. Hence, it is apparent that AOA are important members of deep-sea sponges in particular, and that different acquisition and maintenance processes may be involved regarding the archaeal symbionts compared to the bacteria.

\section{DATA AVAILABILITY STATEMENT}

Sequences were deposited at NCBI as BioProjects with accession IDs PRJNA552490 and PRJNA552540.

\section{AUTHOR CONTRIBUTIONS}

PS, UH, KaB, and GS designed the experiments. GS, $\mathrm{KaB}, \mathrm{KrB}$, GW, PS, SK, and PA performed the experiments. GS, DE, KaB, $\mathrm{KrB}, \mathrm{UH}$, and PS analyzed the data. GS, KaB, KrB, PS, and $\mathrm{UH}$ wrote the manuscript. GS, GW, KaB, KrB, MD, SM, UH, and PS reviewed and edited the manuscript. MD identified hexactinellid specimens. MK identified demosponge specimens. SM provided initial identification and curation of taxonomic vouchers of sponges. 


\section{FUNDING}

This study was funded by the European Union's Horizon 2020 Research and Innovation Program to UH under Grant Agreement No. 679849 ('SponGES') and by the DFG Collaborative Research Center CRC1182-TP B1 ("Metaorganisms") to UH. PS acknowledges funding by the Federal Ministry of Education and Research (BMBF) for the cruise SO254, grant 03G0254A, PORIBACNEWZ. GW acknowledges funding by LMU Munich's Institutional Strategy LMU excellent within the framework of the German Excellence Initiative.

\section{ACKNOWLEDGMENTS}

This work is dedicated to Hans Tore Rapp, coordinator of the H2020-SponGES project, mentor and friend. We thank Andrea Hethke, Ina Clefsen, and the CRC1182 Z3 team (Katja Cloppenborg-Schmidt, Malte Rühlemann, John Baines) for assistance with the amplicon pipeline. We greatly acknowledge the crew and scientific party of $\mathrm{RV}$ Sonne cruise SO254, as well as the ROV Kiel 6000 team for their valuable support at sea. We also thank Sven Rohde, Tessa Clemens and the entire benthic invertebrate team of the RV Sonne Cruise SO254 for their assistance in sample collection, processing and cataloging. We thank Henry Reiswig for advice on identification of hexactinellid samples. Sample collection was carried out under the "Application for consent to conduct marine scientific research in areas under national jurisdiction of New Zealand (dated 7.6.2016)." This is publication 68 of Senckenberg am Meer Metabarcoding and Molecular Laboratory. We also thank

\section{REFERENCES}

Bayer, K., Kamke, J., and Hentschel, U. (2014). Quantification of bacterial and archaeal symbionts in high and low microbial abundance sponges using real-time PCR. FEMS Microbiol. Ecol. 89, 679-690. doi: 10.1111/1574-6941. 12369

Bayer, K., Schmitt, S., and Hentschel, U. (2008). Physiology, phylogeny and in situ evidence for bacterial and archaeal nitrifiers in the marine sponge Aplysina aerophoba. Environ. Microbiol. 10, 2942-2955. doi: 10.1111/j.1462-2920.2008. 01582.x

Borchert, E., Selvin, J., Kiran, S. G., Jackson, S. A., O'Gara, F., and Dobson, A. D. W. (2017). A novel cold active esterase from a deep sea sponge stelletta normani metagenomic library. Front. Mar. Sci. 4:287. doi: 10.3389/fmars.2017. 00287

Boylen, E., Rideout, J. R., Dillon, M. R., Bokulich, N. A., Abnet, C. C., Gabriel, A., et al. (2018). QIIME 2: reproducible, interactive, scalable, and extensible microbiome data science. PeerJ Prepr. 37, 852-857. doi: 10.7287/peerj.preprints. $27295 \mathrm{v} 2$

Burgsdorf, I., Erwin, P. M., López-Legentil, S., Cerrano, C., Haber, M., Frenk, S., et al. (2014). Biogeography rather than association with cyanobacteria structures symbiotic microbial communities in the marine sponge Petrosia ficiformis. Front. Microbiol. 5:529. doi: 10.3389/fmicb.2014.00529

Bustin, S. A., Benes, V., Garson, J. A., Hellemans, J., Huggett, J., Kubista, M., et al. (2009). The MIQE guidelines: minimum information for publication of the reviewers for their comments, which helped to improve this manuscript.

\section{SUPPLEMENTARY MATERIAL}

The Supplementary Material for this article can be found online at: https://www.frontiersin.org/articles/10.3389/fmicb. 2020.00716/full\#supplementary-material

FIGURE S1 | Pictures of the freshly collected sponges, including one picture of the whole specimen and one close-up picture. Demospongiae: $\mathbf{( A , B )}=$ Pleroma turbinatum Sollas, 1888; (C,D) = Latrunculia sp. nov.; (E,F) = Paratimea sp. indet; $\mathbf{( G , H )}=$ Penares turmericolor Sim-Smith and Kelly, 2019; $\mathbf{( I , J ) = ~ G e o d i a ~ v a u b a n i ~}$ Lévi and Lévi, 1983; (K,L) = Halichondria sp. indet. Hexactinellida:

$\mathbf{( A , B )}=$ Aphrocallistes beatrix Gray, 1858; $\mathbf{( C , D )}=$ Bolosoma cyanae Tabachnick and Lévi, 2004; (E,F) = Corbitella plagiariorum Reiswig and Kelly, 2018;

$\mathbf{( G , H ) ~ = ~ L a n u g i n e l l i n a e ~ g e n . ~ e t ~ s p . ~ i n d e t ; ~}(\mathbf{I}, \mathbf{J})=$ Leucopsacus distantus Tabachnick and Lévi, 2004; (K,L) = Regadrella okinoseana ljima, 1896; (M,N) = Saccocalyx tetractinus Reiswig and Kelly, 2018.

FIGURE S2 | Alpha diversity plots of bacterial and archaeal communities. Following indices are shown: $(\mathbf{A}, \mathbf{B})=$ Faith's PD; $(\mathbf{C}, \mathbf{D})=$ observed features; $\mathbf{( E , F )}=$ Shannon diversity; $\mathbf{( G , H )}=$ Pielou's evenness.

FIGURE S3 | Principal component analysis using bacterial and archaeal weighted uniFrac distances for Demospongiae (A,B), Hexactinellida (C,D), and seawater (E,F) samples.

Figure S4 | 16S rRNA gene copy numbers of (A) bacterial and (B) archaeal quantitative real-time PCR data.

TABLE S1 | Detailed sampling list, including internal sampling IDs, ROV site IDs, coordinates, and list of seawater samples.

TABLE S2 | Archaeal relative abundances at phylum level.

TABLE S3 | Quantitative real-time PCR efficiency values.

TABLE S4 | Quantitative real-time PCR raw results. Including Qubit measurements, eubacterial 16S rRNA gene copy numbers, eubacterial 16S rRNA gene copy numbers $/ \mu \mathrm{g}$, and ratios.

quantitative real-time PCR experiments. Clin Chem. 622, 611-622. doi: 10.1373/ clinchem.2008.112797

Callahan, B. J., Mcmurdie, P. J., Rosen, M. J., Han, A. W., Johnson, A. J. A., and Holmes, S. P. (2016). DADA2: high-resolution sample inference from Illumina amplicon data. Nat. Methods 13, 581-583. doi: 10.1038/nmeth.3869

Cárdenas, C. A., Font, A., Steinert, G., Rondon, R., and González-Aravena, M. (2019). Temporal stability of bacterial communities in antarctic sponges. Front. Microbiol. 10:2699. doi: 10.3389/fmicb.2019.02699

Cárdenas, C. A., González-aravena, M., and Font, A. (2018). High similarity in the microbiota of cold- water sponges of the genus mycale from two different geographical areas. PeerJ 6:e4935. doi: 10.7717/peerj.4935

Carter, L. (2001). Lessons of the past - currents of change: the ocean flow in a changing world. Water Atmos. 4, 15-17.

Cleary, D. F. R., Polónia, A. R. M., and de Voogd, N. J. (2018). Prokaryote composition and predicted metagenomic content of two cinachyrella morphospecies and water from west papuan marine lakes. FEMS Microbiol. Ecol. 94: fix175. doi: 10.1093/femsec/fix175

de Goeij, J. M., Lesser, M. P., and Pawlik, J. R. (2017). "Nutrient fluxes and ecological functions of coral reef sponges in a changing ocean," in Climate Change, Ocean Acidification and Sponges, eds J. L. Carballo and J. J. Bell (Berlin: Springer), 373-410. doi: 10.1007/978-3-319-59008-0_8

Easson, C. G., and Thacker, R. W. (2014). Phylogenetic signal in the community structure of host-specific microbiomes of tropical marine sponges. Front. Microbiol. 5:532. doi: 10.3389/fmicb.2014.00532 
Erwin, P. M., and Thacker, R. W. (2008). Phototrophic nutrition and symbiont diversity of two caribbean sponge-cyanobacteria symbioses. Mar. Ecol. Prog. Ser. 362, 139-147. doi: 10.3354/meps07464

Fan, L., Reynolds, D., Liu, M., Stark, M., Kjelleberg, S., Webster, N. S., et al. (2012). Functional equivalence and evolutionary convergence in complex communities of microbial sponge symbionts. Proc. Natl. Acad. Sci. U.S.A. 109, E1878-E1887. doi: $10.1073 /$ pnas. 1203287109

Feng, G., and Li, Z. (2019). "Carbon and nitrogen metabolism of sponge microbiome," in Symbiotic Microbiomes of Coral Reefs Sponges and Corals, ed. Z. Li (Dordrecht: Springer), doi: 10.1007/978-94-024-1612-1_9

Feng, G., Sun, W., Zhang, F., Karthik, L., and Li, Z. (2016). Inhabitancy of active nitrosopumilus-like ammonia-oxidizing archaea and Nitrospira nitriteoxidizing bacteria in the sponge Theonella swinhoei. Sci. Rep. 6:24966. doi: 10.1038/srep24966

Feng, G., Sun, W., Zhang, F., Orlić, S., and Li, Z. (2018). Functional transcripts indicate phylogenetically diverse active ammonia-scavenging microbiota in sympatric sponges. Mar. Biotechnol. 20, 131-143. doi: 10.1007/s10126-0189797-9795

Gantner, S., Andersson, A. F., Alonso-Sáez, L., and Bertilsson, S. (2011). Novel primers for $16 \mathrm{~S}$ rRNA-based archaeal community analyses in environmental samples. J. Microbiol. Methods 84, 12-18. doi: 10.1016/j.mimet.2010.10.001

Garrison, T. S. (2009). Oceanography: An Invitation to Marine Science. Boston, MA: Cengage Learning.

Gray, J. E. (1858). On aphrocallistes, a new genus of spongiadae from malacca. Proc. Zool. Soc. Lond. 26, 114-115. doi: 10.1111/j.1469-7998.1858.tb06 352.x

Hallam, S. J., Konstantinidis, K. T., Putnam, N., Schleper, C., Watanabe, Y., Sugahara, J., et al. (2006). Genomic analysis of the uncultivated marine crenarchaeote Cenarchaeum symbiosum. Proc. Natl. Acad. Sci. U.S.A. 103, 18296-18301. doi: 10.1073/pnas.0608549103

Helber, S. B., Steinert, G., Wu, Y.-C., Rohde, S., Hentschel, U., Muhando, C. A., et al. (2019). Sponges from Zanzibar host diverse prokaryotic communities with potential for natural product synthesis. FEMS Microbiol. Ecol. 95:fiz026. doi: 10.1093/femsec/fiz026

Hoffmann, F., Radax, R., Woebken, D., Holtappels, M., Lavik, G., Rapp, H. T., et al. (2009). Complex nitrogen cycling in the sponge Geodia barretti. Environ. Microbiol. 11, 2228-2243. doi: 10.1111/j.1462-2920.2009.01944.x

Ijima, I. (1896). Notice of new hexactinellida from sagami bay. Zool. Anzeiger. 19, 249-254.

Jackson, S. A., Flemer, B., McCann, A., Kennedy, J., Morrissey, J. P., O’Gara, F., et al. (2013). Archaea appear to dominate the microbiome of inflatella pellicula deep sea sponges. PLoS One 8:84438. doi: 10.1371/journal.pone.0084438

Kennedy, J., Flemer, B., Jackson, S. A., Morrissey, J. P., O’Gara, F., and Dobson, A. D. W. (2014). Evidence of a putative deep sea specific microbiome in marine sponges. PLoS One 9:e091092. doi: 10.1371/journal.pone.0091092

Könneke, M., Schubert, D. M., Brown, P. C., Hügler, M., Standfest, S., Schwander, T., et al. (2014). Ammonia-oxidizing archaea use the most energy-efficient aerobic pathway for CO2 fixation. Proc. Natl. Acad. Sci. U.S.A. 111, 8239-8244. doi: 10.1073/pnas.1402028111

Lee, O. O., Wang, Y., Yang, J., Lafi, F. F., Al-Suwailem, A., and Qian, P.-Y. (2010). Pyrosequencing reveals highly diverse and species-specific microbial communities in sponges from the Red Sea. ISME J. 5, 650-664. doi: 10.1038/ ismej.2010.165

Lévi, C., and Lévi, P. (1983). Eponges tétractinellides et lithistides bathyales de nouvelle-calédonie. Bull. Mus. Natl. Nat. 5, 101-168.

Li, Z.-Y., Wang, Y.-Z., He, L.-M., and Zheng, H.-J. (2014). Metabolic profiles of prokaryotic and eukaryotic communities in deep-sea sponge Lamellomorpha sp. indicated by metagenomics. Sci. Rep. 4, 1-11. doi: 10.1038/srep03895

Liu, M., Fan, L., Zhong, L., Kjelleberg, S., and Thomas, T. (2012). Metaproteogenomic analysis of a community of sponge symbionts. ISME J. 6, 1515-1525. doi: 10.1038/ismej.2012.1

Lurgi, M., Thomas, T., Wemheuer, B., Webster, N. S., and Montoya, J. M. (2019). Modularity and predicted functions of the global sponge-microbiome network. Nat. Commun. 10:992. doi: 10.1038/s41467-019-08925-8924

Moeller, F. U., Webster, N. S., Herbold, C. W., Behnam, F., Domman, D., Albertsen, M., et al. (2019). Characterization of a thaumarchaeal symbiont that drives incomplete nitrification in the tropical sponge ianthella basta originalitysignificance statement. bioRxiv [Preprint], doi: 10.1101/527234
Moitinho-Silva, L., Bayer, K., Cannistraci, C. V., Giles, E. C., Ryu, T., Seridi, L., et al. (2014). Specificity and transcriptional activity of microbiota associated with low and high microbial abundance sponges from the Red Sea. Mol. Ecol. 23, 1348-1363. doi: 10.1111/mec.12365

Moitinho-Silva, L., Díez-Vives, C., Batani, G., Esteves, A. I., Jahn, M. T., and Thomas, T. (2017a). Integrated metabolism in sponge-microbe symbiosis revealed by genome-centered metatranscriptomics. ISME J. 11, 1651-1666. doi: 10.1038/ismej.2017.25

Moitinho-Silva, L., Nielsen, S., Amir, A., Gonzalez, A., Ackermann, G. L., Cerrano, C., et al. (2017b). The sponge microbiome project. Gigascience 6, 1-7. doi: 10.1093/gigascience/gix077

Moitinho-Silva, L., Steinert, G., Nielsen, S., Hardoim, C. C. P., Wu, Y.-C., McCormack, G. P., et al. (2017c). Predicting the HMA-LMA status in marine sponges by machine learning. Front. Microbiol. 8:752. doi: 10.3389/fmicb.2017. 00752

Naim, M. A., Morillo, J. A., Sørensen, S. J., Waleed, A. A. S., Smidt, H., and Sipkema, D. (2014). Host-specific microbial communities in three sympatric North Sea sponges. FEMS Microbiol. Ecol. 90, 390-403. doi: 10.1111/1574-6941. 12400

Nearing, J. T., Douglas, G. M., Comeau, A. M., and Langille, M. G. I. (2018). Denoising the Denoisers: an independent evaluation of microbiome sequence error-correction approaches. PeerJ 6:e5364. doi: 10.7717/peerj.5364

Øvreås, L., Forney, L., Daae, F. L., and Torsvik, V. (1997). Distribution of bacteroplankton in meromictic lake Saelenvannet, as determined by denaturing gradient gel electrophoresis of PCR-amplified gene fragments coding for $16 \mathrm{~S}$ rRNA. Appl. Environ. Microbiol. 63, 3367-3373. doi: 10.1128/aem.63.9.33673373.1997

Pape, T., Hoffmann, F., Quéric, N. V., Von Juterzenka, K., Reitner, J., and Michaelis, W. (2006). Dense populations of Archaea associated with the demosponge Tentorium semisuberites schmidt, 1870 from Arctic deep-waters. Pol. Biol. 29, 662-667. doi: 10.1007/s00300-005-0103-104

Parks, D. H., Chuvochina, M., Waite, D. W., Rinke, C., Skarshewski, A., Chaumeil, P. A., et al. (2018). A standardized bacterial taxonomy based on genome phylogeny substantially revises the tree of life. Nat. Biotechnol. 36:996. doi: 10.1038/nbt.4229

Pita, L., Rix, L., Slaby, B. M., Franke, A., and Hentschel, U. (2018). The sponge holobiont in a changing ocean: from microbes to ecosystems. Microbiome 6:46. doi: 10.1186/s40168-018-0428-421

Pita, L., Turon, X., López-Legentil, S., and Erwin, P. M. (2013). Host rules: spatial stability of bacterial communities associated with marine sponges (ircinia spp.) in the western mediterranean Sea. FEMS Microbiol. Ecol. 86, 268-276. doi: 10.1111/1574-6941.12159

Radax, R., Hoffmann, F., Rapp, H. T., Leininger, S., and Schleper, C. (2012). Ammonia-oxidizing archaea as main drivers of nitrification in cold-water sponges. Environ. Microbiol. 14, 909-923. doi: 10.1111/j.1462-2920.2011.02661. $\mathrm{x}$

Reiswig, H. M., and Kelly, M. (2018). The marine fauna of New Zealand. Euplectellid glass sponges (Hexactinellida, Lyssacinosida, Euplectellidae). NIWA Biodiver. Mem. 130, 1-170.

Reveillaud, J., Maignien, L., Eren, M., Huber, J. A., Apprill, A., Sogin, M. L., et al. (2014). Host-specificity among abundant and rare taxa in the sponge microbiome. ISME J. 8, 1198-1209. doi: 10.1038/ismej.2013.227

Ribes, M., Jiménez, E., Yahel, G., López-Sendino, P., Diez, B., Massana, R., et al. (2012). Functional convergence of microbes associated with temperate marine sponges. Environ. Microbiol. 14, 1224-1239. doi: 10.1111/j.1462-2920.2012. 02701.x

Rodríguez-Marconi, S., De la Iglesia, R., Díez, B., Fonseca, C. A., Hajdu, E., and Trefault, N. (2015). Characterization of bacterial, archaeal and eukaryote symbionts from antarctic sponges reveals a high diversity at a three-domain level and a particular signature for this ecosystem. PLoS One 10:e138837. doi: 10.1371/journal.pone.0138837

Schläppy, M. L., Schöttner, S. I., Lavik, G., Kuypers, M. M. M., de Beer, D., and Hoffmann, F. (2010). Evidence of nitrification and denitrification in high and low microbial abundance sponges. Mar. Biol. 157, 593-602. doi: 10.1007/ s00227-009-1344-1345

Schloss, P. D., Westcott, S. L., Ryabin, T., Hall, J. R., Hartmann, M., Hollister, E. B., et al. (2009). Introducing mothur: open-source, platform-independent, community-supported software for describing and comparing microbial 
communities. Appl. Environ. Microbiol. 75, 7537-7541. doi: 10.1128/AEM. 01541- 1549

Schmitt, S., Tsai, P., Bell, J., Fromont, J., Ilan, M., Lindquist, N., et al. (2012). Assessing the complex sponge microbiota: core, variable and species-specific bacterial communities in marine sponges. ISME J. 6, 564-576. doi: 10.1038/ ismej.2011.116

Sharp, K. H., Eam, B., John Faulkner, D., and Haygood, M. G. (2007). Vertical transmission of diverse microbes in the tropical sponge Corticium sp. Appl. Environ. Microbiol. 73, 622-629. doi: 10.1128/AEM.01493-1496

Sim-Smith, C., and Kelly, M. (2019). Review of the sponge genus penares (demospongiae, tetractinellida, astrophorina) in the New Zealand EEZ, with descriptions of new species. Zootaxa 4638, 1-56. doi: 10.11646/zootaxa.4638. 1.1

Slaby, B. M., Franke, A., Rix, L., Pita, L., Bayer, K., Jahn, M. T., et al. (2019). "Marine sponge holobionts in health and disease," in Symbiotic Microbiomes of Coral Reefs Sponges and Corals, ed. Z. Li (Dordrecht: Springer), 81-104. doi: 10.1007/978-94-024-1612-1

Sollas, W. J. (1888). Report on the Tetractinellida collected by H.M.S. challenger, during the years 1873-1876. report on the scientific results of the voyage of H.M.S. challenger during the years 1873-76. Zoology 25, 1-44.

Steger, D., Ettinger-Epstein, P., Whalan, S., Hentschel, U., De Nys, R., Wagner, M., et al. (2008). Diversity and mode of transmission of ammonia-oxidizing archaea in marine sponges. Environ. Microbiol. 10, 1087-1094. doi: 10.1111/j. 1462-2920.2007.01515.x

Steinert, G., Rohde, S., Janussen, D., Blaurock, C., and Schupp, P. J. (2017). Hostspecific assembly of sponge-associated prokaryotes at high taxonomic ranks. Sci. Rep. 7:2542. doi: 10.1038/s41598-017-02656-2656

Steinert, G., Taylor, M. W., Deines, P., Simister, R. L., de Voogd, N. J., Hoggard, M., et al. (2016). In four shallow and mesophotic tropical reef sponges from guam the microbial community largely depends on host identity. PeerJ 4:e1936. doi: $10.7717 /$ peerj.1936

Steinert, G., Wemheuer, B., Janussen, D., Erpenbeck, D., Daniel, R., Simon, M., et al. (2019). Prokaryotic diversity and community patterns in antarctic continental shelf sponges. Science 6, 1-15. doi: 10.3389/fmars.2019.00297

Tabachnick, K. R., and Lévi, C. (2004). "Lyssacinosida du Pacifique sud-ouest (Porifera: Hexactinellida)," in Tropical Deep-Sea Benthos 23. Mémoires du Muséum National d'Histoire Naturelle, Vol. 191, eds B. A. Marshall and B. Richer de Forges (Dordrecht: Springer), 11-71.

Takahashi, S., Tomita, J., Nishioka, K., Hisada, T., and Nishijima, M. (2014). Development of a prokaryotic universal primer for simultaneous analysis of bacteria and archaea using next-generation sequencing. PLoS One 9:e105592. doi: 10.1371/journal.pone.0105592

Taylor, M. W., Tsai, P., Simister, R. L., Deines, P., Botte, E., Ericson, G., et al. (2013). 'Sponge-specific' bacteria are widespread (but rare) in diverse marine environments. ISME J. 7, 438-443. doi: 10.1038/ismej.2012.111

That, T., Dat, H., Steinert, G., Thi, N., Cuc, K., Smidt, H., et al. (2018). Archaeal and bacterial diversity and community composition from 18 phylogenetically divergent sponge species in Vietnam. PeerJ 6:e4970. doi: 10.7717/peerj.4970

Thomas, T., Moitinho-Silva, L., Lurgi, M., Björk, J. R., Easson, C., Astudillo-García, C., et al. (2016). Diversity, structure and convergent evolution of the global sponge microbiome. Nat. Commun. 7:11870. doi: 10.1038/ncomms11870
Tian, R. M., Sun, J., Cai, L., Zhang, W. P., Zhou, G. W., Qiu, J. W., et al. (2016). The deep-sea glass sponge Lophophysema eversa harbours potential symbionts responsible for the nutrient conversions of carbon, nitrogen and sulfur. Environ. Microbiol. 18, 2481-2494. doi: 10.1111/1462-2920.13161

Torre, D., Forest, L., Wa, P., Kobelt, J. N., Wa, S., Stahl, D. A., et al. (2016). Candidatus Nitrosopumilaceae. Hoboken, NJ: Wiley. doi: 10.1002/ 9781118960608.fbm00262

Vacelet, J. (1975). Etude en microscopie electronique de l'association entre bacteries et spongiaires du genre Verongia (Dictyoceratida). J. Microsc.Biol. Cell $23,271-288$.

Vacelet, J., and Donadey, C. (1977). Electron microscope study of the association between some sponges and bacteria. J. Exp. Mar. Biol. Ecol. 30, 301-314. doi: 10.1016/0022-0981(77)90038-7

van Soest, R. W. M., Boury-Esnault, N., Vacelet, J., Dohrmann, M., Erpenbeck, D., de Voogd, N. J., et al. (2012). Global diversity of sponges (Porifera). PLoS One 7:35105. doi: 10.1371/journal.pone.0035105

Vogel, S. (1977). Current-induced flow through living sponges in nature. Proc. Natl. Acad. Sci. U.S.A. 74, 2069-2071. doi: 10.1073/pnas.74.5.2069

Webster, N. S., Negri, A. P., Munro, M. M. H. G., and Battershill, C. N. (2004). Diverse microbial communities inhabit Antarctic sponges. Environ. Microbiol. 6, 288-300. doi: 10.1111/j.1462-2920.2004.00570.x

Webster, N. S., Taylor, M. W., Behnam, F., Lücker, S., Rattei, T., Whalan, S., et al. (2010). Deep sequencing reveals exceptional diversity and modes of transmission for bacterial sponge symbionts. Environ. Microbiol. 12, 20702082. doi: 10.1111/j.1462-2920.2009.02065.x

Webster, N. S., and Thomas, T. (2016). The sponge hologenome. mBio 7:e00135-16. doi: $10.1128 / \mathrm{mBio} .00135-116$

Wickham, H. (2016). ggplot2: Elegant Graphics for Data Analysis. New York: Springer-Verlag.

Wuchter, C., Schouten, S., and Coolen, M. J. L. (2004). Temperaturedependent variation in the distribution of tetraether membrane lipids of marine crenarchaeota: implications for for TEX86 paleothermometry. Paleoceanography 19:A4028. doi: 10.1029/2004PA001041

Xin, Y., Kanagasabhapathy, M., Janussen, D., Xue, S., and Zhang, W. (2011). Phylogenetic diversity of gram-positive bacteria cultured from antarctic deepsea sponges. Pol. Biol. 34, 1501-1512. doi: 10.1007/s00300-011-1009-y

Conflict of Interest: The authors declare that the research was conducted in the absence of any commercial or financial relationships that could be construed as a potential conflict of interest.

The reviewer NV declared several past co-authorship with the authors DE and GW to the handling editor.

Copyright (c) 2020 Steinert, Busch, Bayer, Kodami, Arbizu, Kelly, Mills, Erpenbeck, Dohrmann, Wörheide, Hentschel and Schupp. This is an open-access article distributed under the terms of the Creative Commons Attribution License (CC BY). The use, distribution or reproduction in other forums is permitted, provided the original author(s) and the copyright owner(s) are credited and that the original publication in this journal is cited, in accordance with accepted academic practice. No use, distribution or reproduction is permitted which does not comply with these terms. 